Prepared in cooperation with the Bureau of Reclamation

\title{
Historical Physical and Chemical Data for Water in Lake Powell and from Glen Canyon Dam Releases, Utah-Arizona, 1964-2013
}

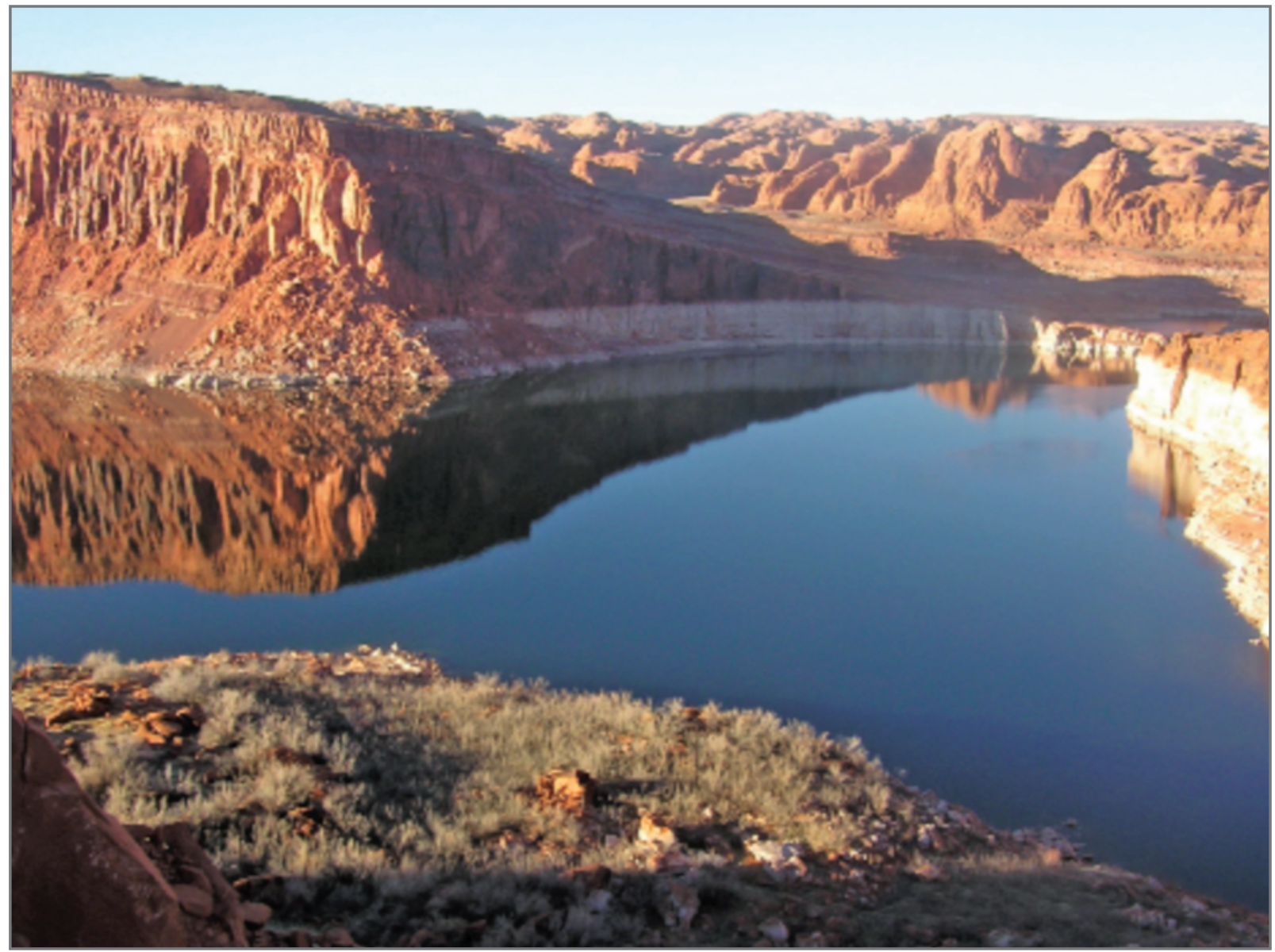

Data Series 471

Version 3.0, February 2015 
COVER:

Photograph of the San Juan River arm of Lake Powell downstream of Wilson Creek, Utah (USGS photograph by William Vernieu.) 


\section{Historical Physical and Chemical Data for Water in Lake Powell and from Glen Canyon Dam Releases, Utah-Arizona, 1964-2013}

By William S. Vernieu

Prepared in cooperation with the Bureau of Reclamation

Data Series 471

Version 3.0, February 2015 


\title{
U.S. Department of the Interior \\ SALLY JEWELL, Secretary
}

\section{U.S. Geological Survey \\ Suzette M. Kimball, Acting Director}

\author{
U.S. Geological Survey, Reston, Virginia \\ First release: 2009 \\ Revised: October 2013 (ver. 2.0) \\ Revised: February 2015 (ver. 3.0)
}

For product and ordering information: World Wide Web: http//www.usgs.gov/pubprod

Telephone: 1-888-ASK-USGS (1-888-275-8747)

For more information on the USGS — the Federal source for science about the Earth, its natural and living resources, natural hazards, and the environment:

World Wide Web: http://www.usgs.gov

Telephone: 1-888-ASK-USGS

Any use of trade, product, or firm names is for descriptive purposes only and does not imply endorsement by the U.S. Government.

Although this report is in the public domain, permission must be secured from the individual copyright owners to reproduce any copyrighted material contained within this report.

Suggested citation:

Vernieu, W.S., 2015, Historical physical and chemical data for water in Lake Powell and from Glen Canyon Dam releases, Utah-Arizona, 1964-2013 (ver. 3.0, February 2015): U.S. Geological Survey Data Series 471, 23 p., http:// dx.doi.org/10.3133/ds471. 


\section{Contents}

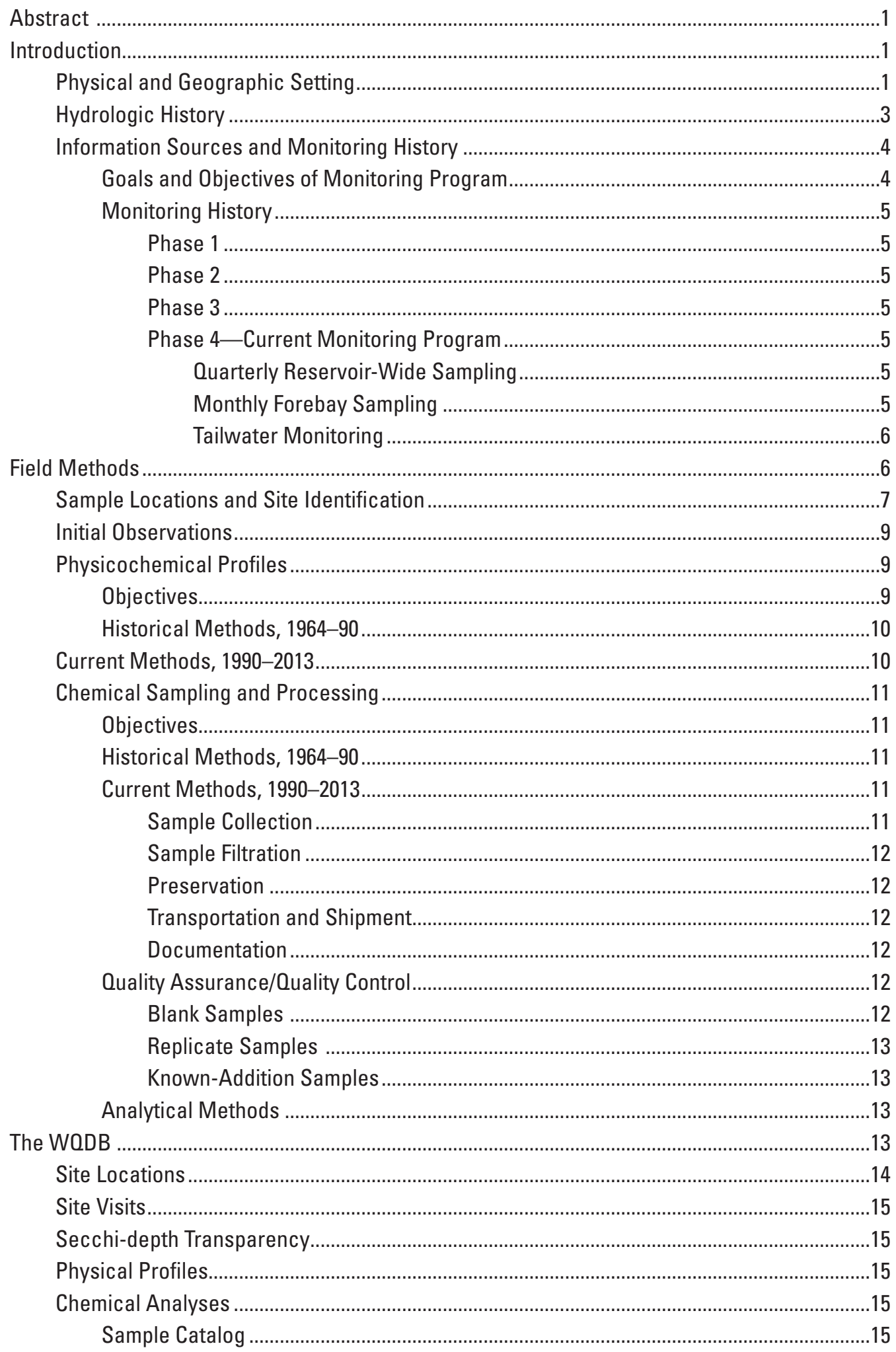




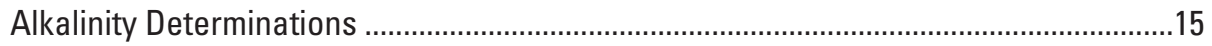

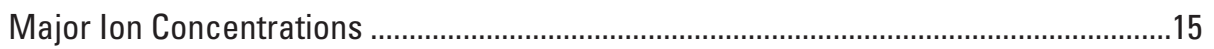

Nutrient Concentrations ……………………………………………………………15

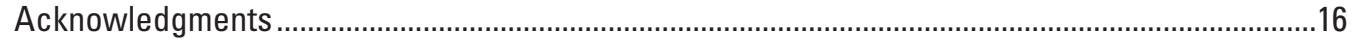

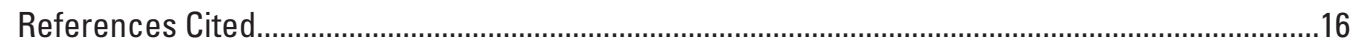

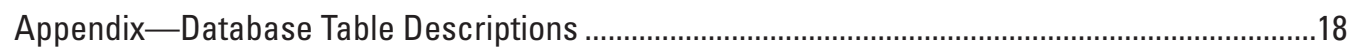

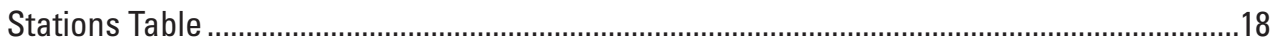

Surface Table

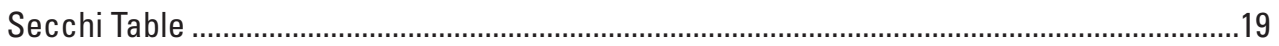

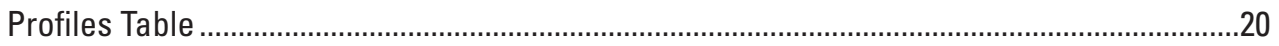

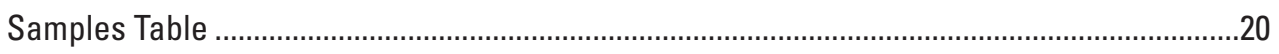

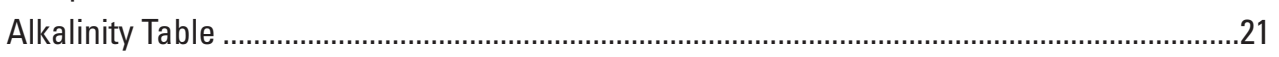

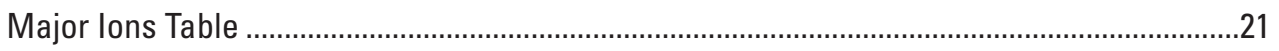

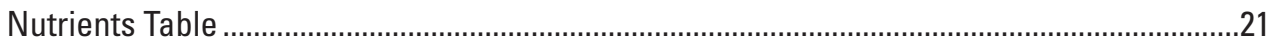

\section{Figures}

1. Lake Powell geographic setting, major tributaries, and water-quality sampling sites.....2

2. Lake Powell historical surface elevation....................................................................

3. Glen Canyon Dam historical water releases....................................................................

4. Entity-relationship diagram for the WODB (water-quality database)................................

\section{Tables}

1. Major features of Lake Powell monitoring program phases...............................................

2. Initial Lake Powell monitoring locations........................................................................

3. Listing of the primary station groups in the WQDB (water-quality database) ..................8

4. Detection limits, units, and U.S. Environmental Protection Agency methods for

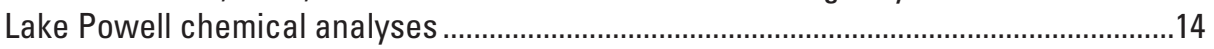

A-1. Data fields and attributes of tblStations .....................................................................19

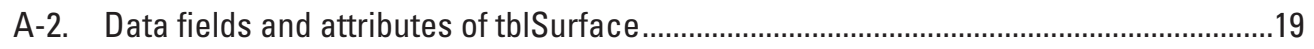

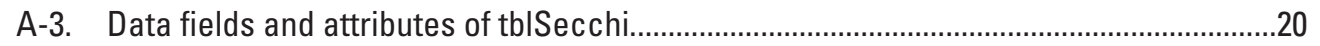

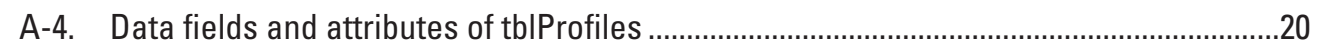

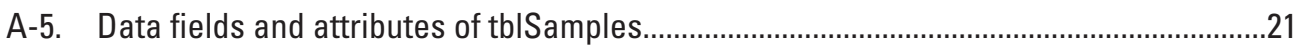

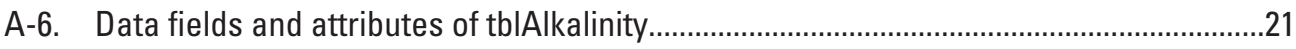

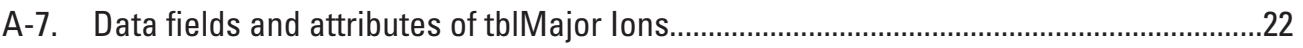

A-8. Data fields and attributes of tblNutrients ....................................................................22 


\title{
Historical Physical and Chemical Data for Water in Lake Powell and from Glen Canyon Dam Releases, Utah- Arizona, 1964-2013
}

\author{
By William S. Vernieu
}

\begin{abstract}
This report presents the physical and chemical characteristics of water in Lake Powell and from Glen Canyon Dam releases from 1964 through 2013. These data are available in a several electronic formats. Data have been collected throughout this period by various offices of the Bureau of Reclamation and U.S. Geological Survey and are compiled to represent the existing body of chemical and physical information on Lake Powell and Glen Canyon Dam releases. From this record, further interpretation may be made concerning mixing processes in Lake Powell, the movement and fate of advective inflow currents, effects of climate and hydrological variations, and the effects of the operation and structure of Glen Canyon Dam on the quality of water in Lake Powell and from Glen Canyon Dam releases.
\end{abstract}

\section{Introduction}

This report presents the physical and chemical data collected and the methods of data collection used by the Bureau of Reclamation (Reclamation) and U.S. Geological Survey (USGS) throughout a 50-year history of Glen Canyon Dam and Lake Powell, from 1964 through 2013. The ongoing monitoring program remains in current operation. The data from this monitoring program are organized in separate tables of the WQDB (a nominal acronym for "water-quality database"). The WQDB is a Microsoft Access relational database, consisting of tables of similar information linked by common fields and was developed to store data and assist in organizing, analyzing, and interpreting this information. Individual data tables contain sampling site information, a catalog of site visits, ambient observations associated with a site visit, depth profiles of physicochemical parameters through the water column, and results of chemical analyses for water samples for major ionic and nutrient constituents. Data from the biological component of the Lake Powell monitoring program will not be presented in this report. Results of continuous monitoring of water-quality conditions below Glen Canyon Dam are reported by Voichick and Wright (2007).

The WQDB and associated files are available at http:// pubs.usgs.gov/ds/471/. These files contain the WQDB Microsoft Access database (WQDB.mbd), comma-separated-values (CSV) files of each of the eight database tables, and CSV files representing the output of predefined sample queries, which combine data from select tables. Further assistance and other data formats are available from the author.

\section{Physical and Geographic Setting}

Glen Canyon Dam was completed on March 13, 1963, and represents the primary storage unit of the Colorado River Storage Project. Glen Canyon Dam, constructed and operated by Reclamation, impounds the Colorado River to form Lake Powell. Lake Powell is located on the border of Utah and Arizona within Glen Canyon National Recreation Area, upstream of Glen Canyon Dam, 2 miles northwest of Page, Ariz. (fig. 1). At a full pool elevation of 1,128 m (3,700 ft), Lake Powell has a capacity of $32.336 \mathrm{~km}^{3}$ (26.214 MAF) (Ferrari, 1988), a surface area of 65,069 ha (160,784 acres), and extends $290 \mathrm{~km}$ (180 miles) upstream, with an estimated shoreline length of $3,057 \mathrm{~km}(1,900 \mathrm{mi})$. The drainage area above Lake Powell is $279,000 \mathrm{~km}^{2}\left(108,000 \mathrm{mi}^{2}\right)$ (Stanford and Ward, 1991).

Glen Canyon Dam can discharge water from three different release structures, located at different elevations. During normal operations, virtually all water is released from Glen Canyon Dam through eight powerplant penstocks, located across the face of the dam at an elevation of $1,058 \mathrm{~m}(3,470 \mathrm{ft})$, with a maximum release capacity of $934 \mathrm{~m}^{3} / \mathrm{s}(33,000 \mathrm{cfs})$. An additional $425 \mathrm{~m}^{3} / \mathrm{s}$ $(15,000 \mathrm{cfs})$ can be released through the river outlet works, which withdraw water at an elevation of $1,028 \mathrm{~m}(3,374 \mathrm{ft})$ through four penstocks controlled by hollow jet valves; this water bypasses the Glen Canyon Dam powerplant. As much as $7,815 \mathrm{~m}^{3} / \mathrm{s}(276,000 \mathrm{cfs})$ may also be discharged from two spillway structures, which route water from near the surface of the reservoir at an elevation of $1,112 \mathrm{~m}(3,648 \mathrm{ft})$ to the river below the dam, at an approximate elevation of $956 \mathrm{~m}(3,135 \mathrm{ft})$, 


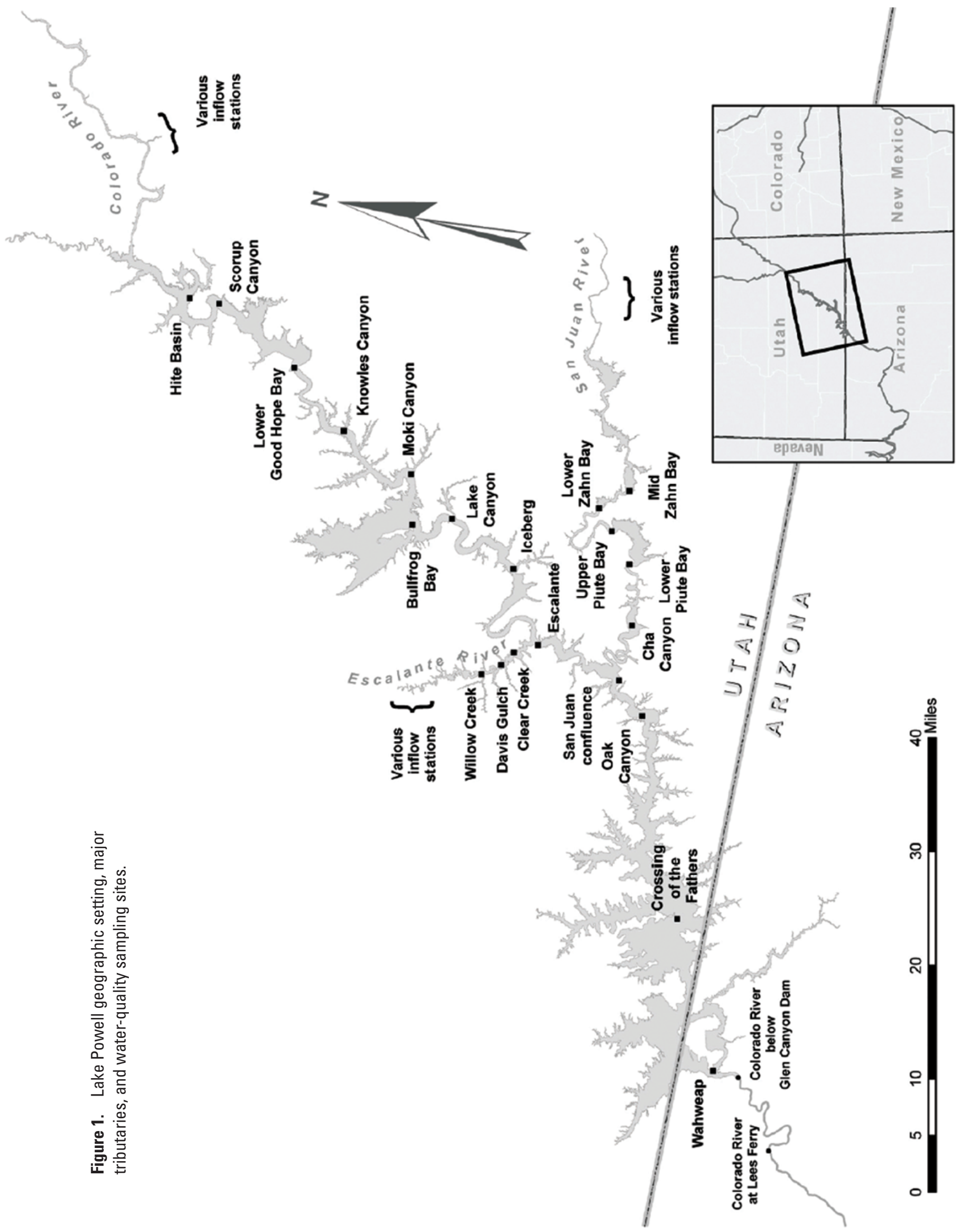


through tunnels in the bedrock on either side of the dam (Bureau of Reclamation, 1981).

\section{Hydrologic History}

Lake Powell began filling on March 13, 1963, when the gates of Glen Canyon Dam were closed. The reservoir experienced a prolonged filling period until the full-pool elevation of $1,128 \mathrm{~m}$ (3,700 ft) was reached on June 22, 1980 (fig. 2). From 1980 to 1987, Lake Powell remained relatively full during a period with above-average inflows. Prolonged drought conditions, in which inflow volumes to Lake Powell were below normal, persisted in the upper Colorado River Basin from 1987 to 1992, and again from 1999 to 2007. As a result, Lake Powell's surface level steadily declined during those periods. During the period from 2000 to 2013, the unregulated inflow to Lake Powell was above average in only 3 of the 14 years, the lowest 14-year period since the closure of the Glen Canyon Dam in 1963. The reservoir reached a minimum level of 1,101.08 m (3,612.46 ft) on February 19,1993 , and a lower minimum level of $1,083.57 \mathrm{~m}(3,555.02 \mathrm{ft})$ on April 8, 2005. The 2005 minimum was Lake Powell's lowest level since 1969. This resulted in a reduction of Lake Powell's volume to $12.166 \mathrm{~km}^{3}$ (9.863 MAF), or 38 percent of its full capacity of $32.335 \mathrm{~km}^{3}$ (26.214 MAF). At the end of 2013, the reservoir was at a level of $1,092.54 \mathrm{~m}(3,586.46 \mathrm{ft})$.
Annual and monthly releases from Glen Canyon Dam are determined by the Annual Operating Plan for Colorado River Reservoirs, which takes into account hydrologic and climatic conditions, most probable water-supply conditions, and downstream delivery requirements.

Before June 1990, daily releases from Glen Canyon Dam were designed to maximize revenues from hydropower production. As a result, discharges from Glen Canyon Dam were generally characterized by large daily fluctuations with maxima at turbine capacity of $892 \mathrm{~m}^{3} / \mathrm{s}(31,500 \mathrm{cfs})$, and minima of $28.3 \mathrm{~m}^{3} / \mathrm{s}(1,000 \mathrm{cfs})$ in winter and $85.0 \mathrm{~m}^{3} / \mathrm{s}(3,000$ cfs) in summer (National Research Council, 1996). High release volumes above powerplant capacity, using the river outlet works and spillway structures, occurred during periods of high inflows and full-reservoir conditions in 1980, 1983, 1984, and 1985.

From June, 1990, through July, 1991, a series of research flows was conducted to determine the effects of various operations on Grand Canyon resources. These flows consisted of various discharge regimes with durations of 2 to 5 weeks, separated by 3-day periods of $142 \mathrm{~m}^{3} / \mathrm{s}$ (5,000 cfs) (Stanford and Ward, 1991). Interim operating criteria were established in August, 1991, which restricted daily minimum and maximum releases and daily and hourly release fluctuations. The 1996 Record of Decision (U.S. Department of the Interior, 1996) adopted these criteria, with slight modification, as the modified low fluctuating flow (MLFF)

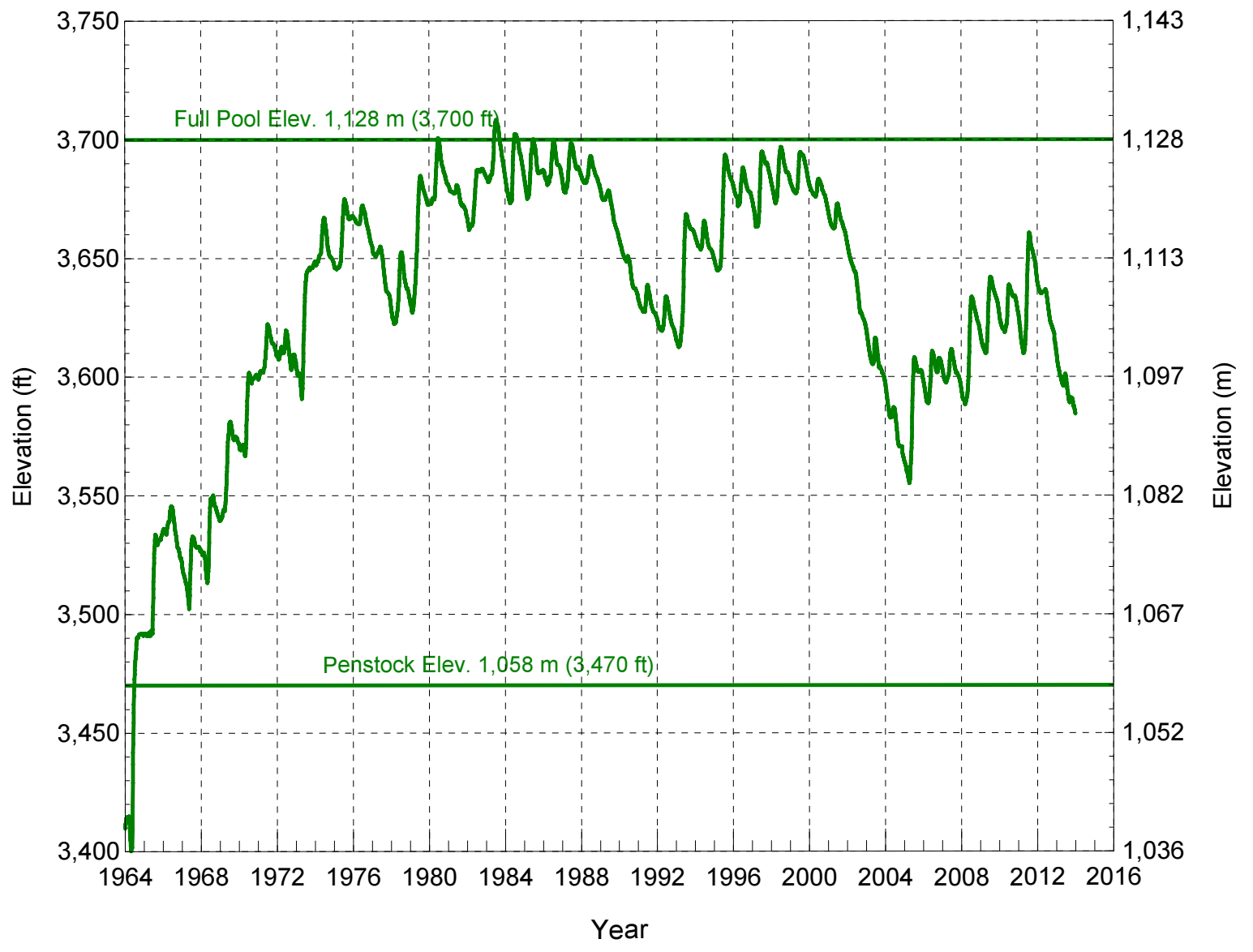

Figure 2. Lake Powell historical surface elevation. $\mathrm{ft}$, feet; $\mathrm{m}$, meters. 
alternative. These release criteria have remained in place to the present, with occasional experimental high-flow releases occurring in 1996, 1997, 2000, 2004, 2008, 2012, and 2013 (fig. 3).

In 2007, the Secretary of the Interior signed the Record of Decision for the Interim Guidelines for the Operation of Lake Powell and Lake Mead (Bureau of Reclamation, 2007). Section 6.C.1 of the Interim Guidelines sets criteria by which annual required releases from the Glen Canyon Dam may be reduced, depending on projected system storage and reservoir water surface elevations. A minimum of $10.15 \mathrm{~km}^{3}$ (8.23 MAF) must be released from Glen Canyon Dam each year, except for reductions specified by Interim Guidelines.

\section{Information Sources and Monitoring History}

\section{Goals and Objectives of Monitoring Program}

Reclamation and USGS have monitored the water quality of Lake Powell and Glen Canyon Dam releases since 1964. The objectives of this monitoring program have changed during this period, reflecting changes in scientific interest in a filling reservoir, responsibilities of Reclamation for maintaining salinity levels in the Colorado River, and more recent environmental concerns related to the Grand Canyon Protection Act, the Glen Canyon Dam Environmental Impact Statement and subsequent Record of Decision, and the establishment of the Glen Canyon Dam Adaptive Management Program.

Objectives of this long-term monitoring program include:

- Status-and-trend determination;

- Documentation of the historical record of Lake Powell water quality during various climatological and hydrological patterns;

- Documentation of the effects of the structure and operation of Glen Canyon Dam on the quality of water in Lake Powell and Glen Canyon Dam releases;

- Integration with Glen Canyon Dam Adaptive Management Program;

- Documentation of the density structure of the water column in the Glen Canyon Dam forebay and other locations in the reservoir;

- Assessment of distribution and patterns of major ionic constituents;

- Assessment of distribution and patterns of nutrient constituents; and

- Assessment of the community structure and status and trends of plankton populations and primary production.

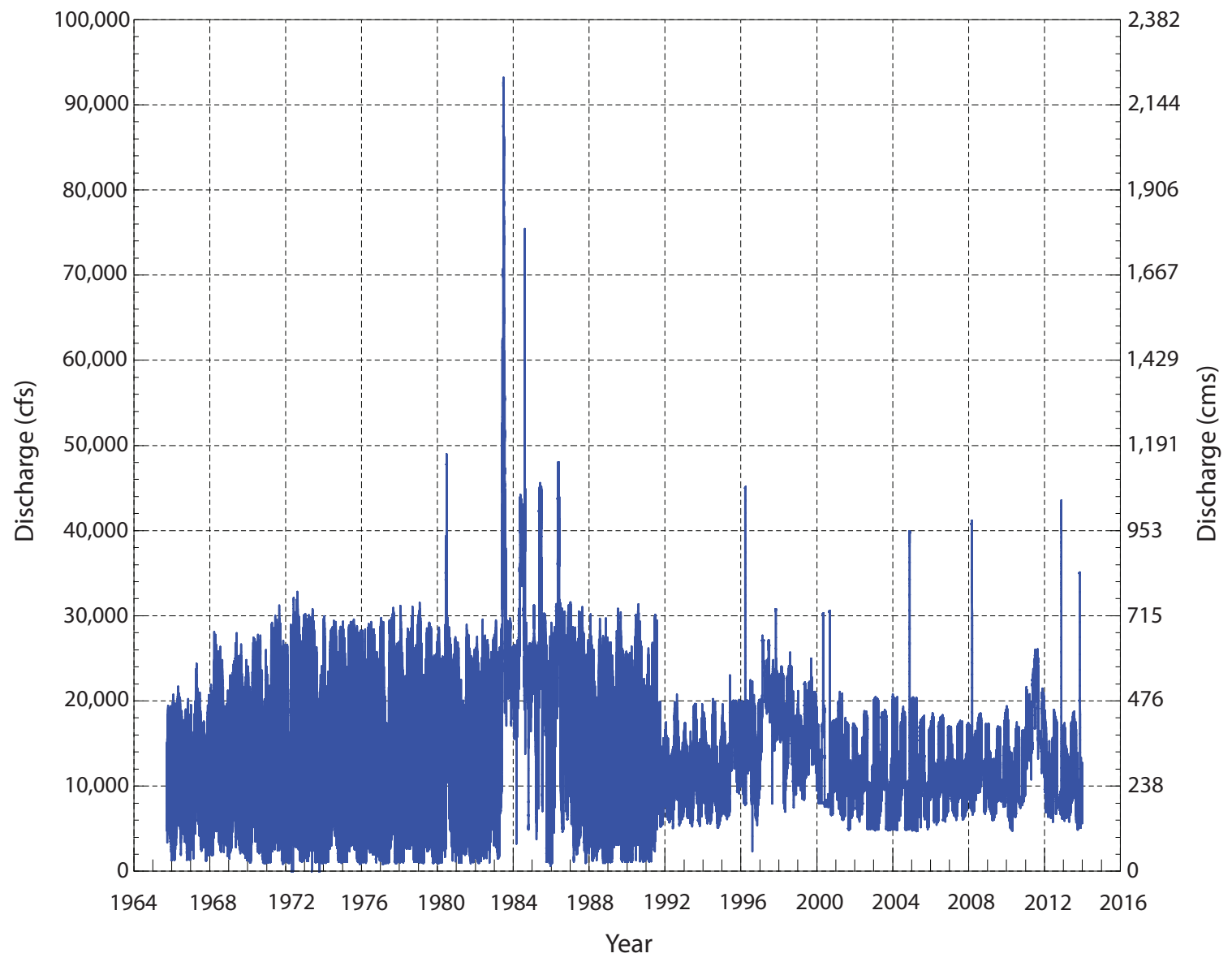

Figure 3. Glen Canyon Dam historical water releases. cfs, cubic feet per second; cms, cubic meters per second. 


\section{Monitoring History}

Reclamation initiated a water-quality monitoring program on Lake Powell in 1964, which has continued to the present, to gather information to describe water-quality conditions and to observe changes in water quality as the reservoir filled and matured. Based on sampling frequency, spatial resolution of measurements, and changes in instrumentation, four distinct phases of monitoring activity can be identified (table 1).

Studies related to Lake Powell were conducted in the 1970s by educational consortiums and Federal and State agencies on topics that include sedimentation, circulation patterns, trace-element chemistry, remote sensing, and publichealth issues (Potter and Drake, 1989). Various agencies and institutions have conducted additional research and monitoring during Lake Powell's recent history (Hart and Sherman, 1996; Marzolf, 1998; Hart, and others, 2005).

\section{Phase 1}

From 1964 to 1971, monthly sampling was conducted in the Glen Canyon Dam forebay and quarterly surveys were conducted throughout the entire reservoir for temperature and salinity. Measurements and samples were collected at 50 -ft depth intervals, corresponding to even $50-\mathrm{ft}$ increments in elevation above mean sea level (for example, $3,500 \mathrm{ft}$, $3,550 \mathrm{ft}, 3,600 \mathrm{ft}$ ), at seven locations in the reservoir.

\section{Phase 2}

From 1972 to 1981, monthly forebay sampling continued; however, the frequency of lake-wide surveys was increased to a monthly interval. Dissolved oxygen was measured electrometrically.

\section{Phase 3}

From 1982 to 1990, sampling activity steadily declined to one reservoir-wide survey per year in 1988 and 1989. Despite the decline in sampling frequency, advances in instrumentation allowed the collection of higher quality data at finer depth resolution. Continuous monitoring of temperature and salinity in the Glen Canyon Dam tailwater was initiated during this period.

\section{Phase 4-Current Monitoring Program}

In 1990, Glen Canyon Environmental Studies (GCES), a science program initiated in 1982 by Reclamation to examine the effects of dam operations on downstream resources, began conducting water-quality monitoring of Lake Powell, with the goal of understanding how physical and chemical processes in Lake Powell and the operation of Glen Canyon Dam influence the quality of water released to the Colorado River in Grand Canyon. Monitoring frequency was returned to monthly forebay surveys and quarterly lake-wide surveys. Forebay monitoring was conducted by the USGS Water Resources Division during the GCES research flow period from 1990 to 1991 (Hart and
Sherman, 1996). Sampling for nutrient chemistry and biological conditions was also initiated in 1990. GCES conducted monitoring from 1990 to 1996. After 1996, the USGS GCMRC conducted Lake Powell water-quality monitoring.

\section{Quarterly Reservoir-Wide Sampling}

Because of characteristic seasonal patterns in the physical and chemical conditions in Lake Powell, reservoirwide sampling was conducted on a quarterly basis. The goal of this monitoring was to describe the physical, chemical, and biological conditions of the major strata of the reservoir in the main Colorado River channel and the primary tributary arms of the San Juan and Escalante Rivers.

Each reservoir survey took place over a weeklong period and consisted of measurements and collection of chemical and biological samples at 21 to 37 established stations, depending on reservoir elevation, along the main channel and major tributary arms. During each site visit, initial observations were recorded (depth, meteorological conditions, Secchi-depth transparency). A profile of the physicochemical parameters of temperature, specific conductance, dissolved oxygen, $\mathrm{pH}$, oxidation-reduction potential, and turbidity was then collected throughout the water column at variable intervals sufficient to define vertical patterns. This information described stratification patterns that separate the layers of the reservoir, location of inflow currents, dissolved oxygen patterns, and overall chemical conditions in the reservoir. Results were recorded on portable data-logging equipment for immediate viewing in the field and automated transfer to data-management systems.

Samples for chemical analysis of major ion and nutrient constituents were collected at designated sites in Lake Powell. Based on the stratification patterns seen from the physical profile, depths for discrete chemical sampling were determined, with the objective being to characterize the major ion and nutrient concentrations in the major layers of the reservoir. Water samples were filtered and preserved immediately in the field for later laboratory analysis. Field alkalinity determinations were performed on water samples collected from 1995 through 2005.

Biological sampling consisted of the collection of surface samples for chlorophyll $a$ and phytoplankton analysis and vertical tows for zooplankton analysis. Data from these activities are not discussed in this report.

\section{Monthly Forebay Sampling}

Monitoring of the forebay of Lake Powell was performed monthly at the Wahweap station (fig. 1), LPCR0024. This site has been sampled throughout Lake Powell's history and was located in the main channel at the confluence with Wahweap Bay, 2.4 channel kilometers upstream of Glen Canyon Dam. Physicochemical profiling was performed and chemical and biological samples, similar to those for designated stations on quarterly surveys, were also collected. 
Table 1. Major features of Lake Powell monitoring program phases.

[DO-dissolved oxygen, $\mathrm{T}$ - temperature, $\mathrm{SC}$ - specific conductance, $\mathrm{ORP}$ - oxidation-reduction potential; ft, feet]

\begin{tabular}{|c|c|c|c|c|}
\hline $\begin{array}{l}\text { Monitoring program } \\
\text { component }\end{array}$ & $\begin{array}{l}\text { Phase } 1 \\
1965-1971\end{array}$ & $\begin{array}{l}\text { Phase } 2 \\
1972-1981\end{array}$ & $\begin{array}{l}\text { Phase } 3 \\
1982-1990\end{array}$ & $\begin{array}{l}\text { Phase } 4 \\
\text { 1990-2013 }\end{array}$ \\
\hline \multicolumn{5}{|l|}{ Frequency: } \\
\hline Forebay & monthly & monthly & quarterly to yearly & monthly \\
\hline Reservoir & quarterly & monthly & quarterly to yearly & quarterly \\
\hline Number of sampled stations & 8 & 8 & $8-10$ & $21-37$ \\
\hline Physicochemical parameters & $\begin{array}{l}\text { temperature, } \mathrm{DO} \\
\text { (Winkler titration), } \\
\text { occasional } \mathrm{SC} \text {, and } \mathrm{pH}\end{array}$ & $\begin{array}{l}\text { temperature, DO } \\
\text { (electrometric) }\end{array}$ & $\begin{array}{l}\text { multiparameter profiling } \\
(\mathrm{T}, \mathrm{SC}, \mathrm{DO}, \mathrm{pH}, \mathrm{ORP})\end{array}$ & $\begin{array}{l}\text { multiparameter profiling } \\
\text { with datalogger (T, SC, } \\
\text { DO, pH, ORP, turbidity) }\end{array}$ \\
\hline Chemical sampling & major ions & major ions & $\begin{array}{l}\text { major ions (field processing } \\
\text { initiated) }\end{array}$ & major ions, nutrients \\
\hline Sampling interval & $50 \mathrm{ft}$ & $50 \mathrm{ft}$ & $50 \mathrm{ft}$ & $\begin{array}{l}\text { variable, representative of } \\
\text { stratification }\end{array}$ \\
\hline Tailwater monitoring & none & none & below dam T, SC & $\begin{array}{l}\text { below dam, Lees Ferry } \\
\mathrm{T}, \mathrm{SC}, \mathrm{DO}, \mathrm{pH}\end{array}$ \\
\hline
\end{tabular}

\section{Tailwater Monitoring}

Sampling of the Glen Canyon Dam tailwater was performed on a monthly basis, immediately below Glen Canyon Dam and at Lees Ferry, 24.9 km (15.5 mi) downstream of Glen Canyon Dam. Measurements of temperature, specific conductance, dissolved oxygen, $\mathrm{pH}$, oxidation-reduction potential, and turbidity were made, and chemical and biological samples similar to those collected at designated reservoir stations on quarterly surveys were collected.

Continuous water-quality data collection was conducted at three locations in the Glen Canyon Dam tailwater. The longest operating station is located immediately downstream of the Glen Canyon Dam powerplant. At this site, a submersible multiparameter sonde was deployed in a perforated pipe on the river-left (the left side of the river when the viewer is facing downstream) wall in the dam's tailrace below the river outlet works. This site has been in operation since August 1988 measuring temperature and specific conductance at intervals of 2 hours or less. Other constituents were gradually added to this collection program: dissolved oxygen monitoring was added in November 1990, and $\mathrm{pH}$ measurements began in July 1995. Continuous monitoring at Lees Ferry began in October 1991, recording temperature, specific conductance, and dissolved oxygen. Measurements of $\mathrm{pH}$ were added in August 1996. Data from continuous monitoring in the Glen Canyon Dam tailwater are not reported in this report. Tailwater temperature data are described by Voichick and Wright (2007).

\section{Field Methods}

Field activities associated with the Lake Powell monitoring program were generally conducted at established main-channel stations throughout the reservoir from a 31-ft Uniflite sedan powered by twin inboard engines, in use since 1970 . This vessel provided workspace for sampling activities on its aft deck and living quarters for a crew of four to six people for weeklong reservoir surveys.

At each station, several activities were conducted to gather information and collect samples representative of the reservoir at that location. Initial observations characteristic of the location and time of sampling were recorded. A depth profile of physical water-quality parameters was recorded. Water samples from several discrete depths were collected and processed for later analysis. Finally, measurements and samples of biological conditions were taken at selected locations in the water column. With the exception of biological sampling activities, these activities are described in detail below.

Throughout this discussion, references will be made to the WQDB, a database that contains the information from the Lake Powell monitoring program. Data from various components of the monitoring program are stored in separate tables of the database. The linkages that exist between the various tables are graphically represented in figure 4 . Further details of the structure and content of each of the specific tables are discussed in the appendix. 


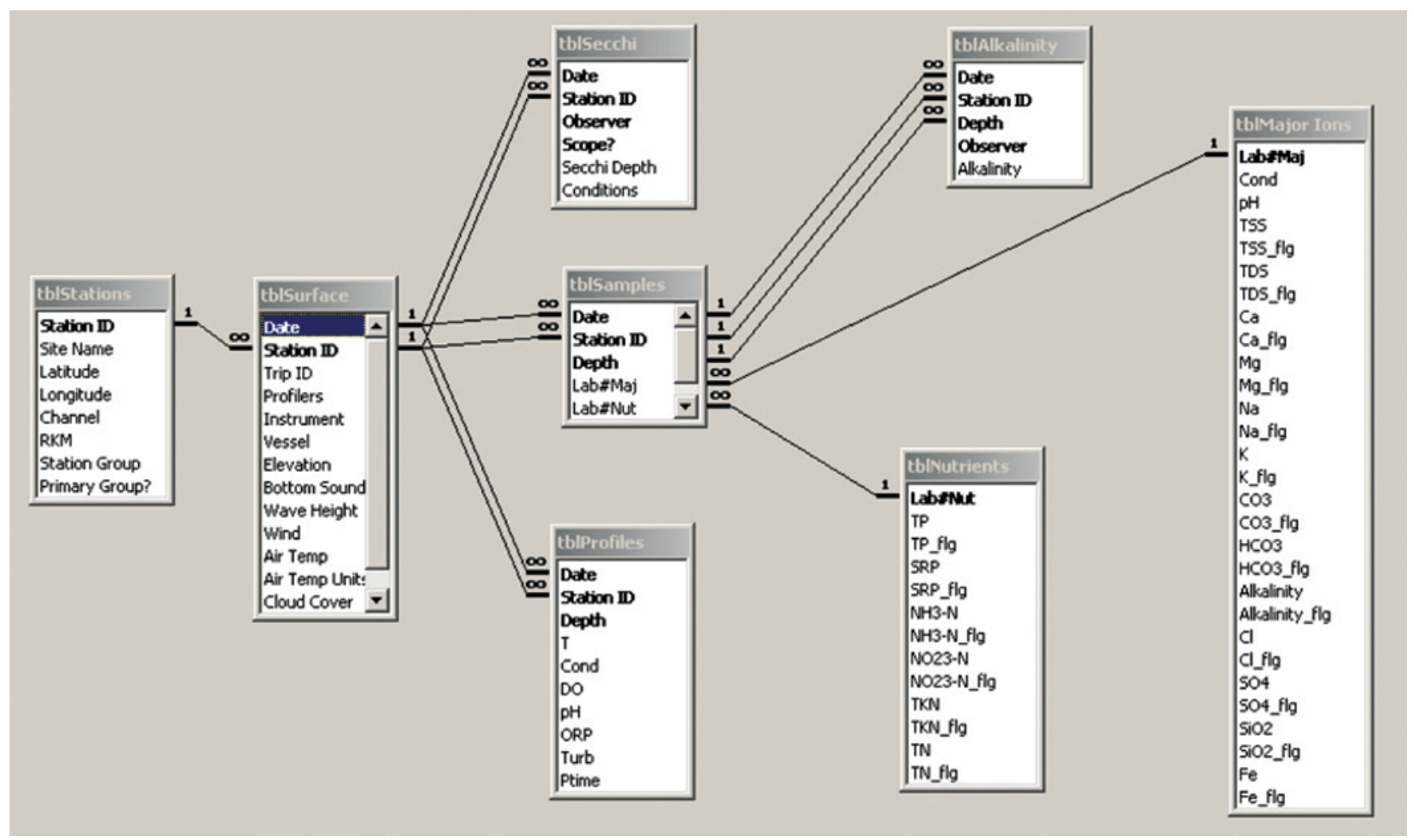

Figure 4. Entity-relationship diagram for the WODB (water-quality database).

\section{Sample Locations and Site Identification}

The Lake Powell monitoring program began in 1964 at six locations in the Colorado River channel and at one location in the San Juan River channel. These sampling locations, the original site identifier codes that were used until 1995, and the current identifier codes that have been used since 1995 are listed in table 2.

In 1992, additional stations were added to the monitoring program to provide greater spatial resolution, especially in the inflow areas of the major tributary arms of the reservoir (Colorado, San Juan, and Escalante Rivers), and to provide regular monitoring of major tributary inflows and Glen Canyon Dam releases. In most cases, sample locations were selected to represent major distinct areas of the reservoir and are located in the thalweg of the original river channel at or near channel constrictions. Thirty-one primary stations have been established at which quarterly monitoring has been or is currently performed (table 3 ). Some primary stations were not always sampled because of low reservoir elevations, and, occasionally other nonprimary stations were sampled where interesting or unusual conditions existed. Currently, 21 to 37 stations may be sampled on a given quarterly survey.

Historically, sampling locations were numbered sequentially in the order of their establishment (column 3, table 3). Under this numbering scheme, there was no information in the station name or code to locate a particular station in reference to another. A revised site-coding scheme was developed in 1995 (column 2, table 3), which allows the location of a station within a particular tributary arm to be determined from its station code. This station-coding scheme and station-group identifiers are described in the appendix.
Table 2. Initial Lake Powell monitoring locations.

[Original Site ID refers to the site identifier in use from 1964 to 1992. Current Site ID refers to the revised site identifier and primary station group in place since 1992]

\begin{tabular}{clc}
\hline $\begin{array}{c}\text { Original } \\
\text { station ID }\end{array}$ & \multicolumn{1}{c}{ Name } & $\begin{array}{c}\text { Current } \\
\text { station ID }\end{array}$ \\
\hline SCUCLP12 & Wahweap & LPCR0024 \\
SCUCLP13 & Crossing of the Fathers & LPCR0453 \\
SCUCLP14 & Oak Canyon & LPCR0905 \\
SCUCLP15 & Cha Canyon (San Juan River) & LPSJR193 \\
SCUCLP16 & Escalante & LPCR1169 \\
SCUCLP17 & Bullfrog & LPCR1692 \\
SCUCLP18 & Hite & LPCR2387 \\
\hline
\end{tabular}


Table 3. Listing of the primary station groups in the WODB (water-quality database).

[Chemical samples are collected at all FULL, LT, TW and INF sites. RKM — river-channel kilometers; Channel Codes: CR - Colorado River, SJR — San Juan River, ESC—Escalante River; Type Codes: INF—inflow site, LT—-long-term site, FULL—full sampling site, PRO—profile-only site, TW—-tailwater site]

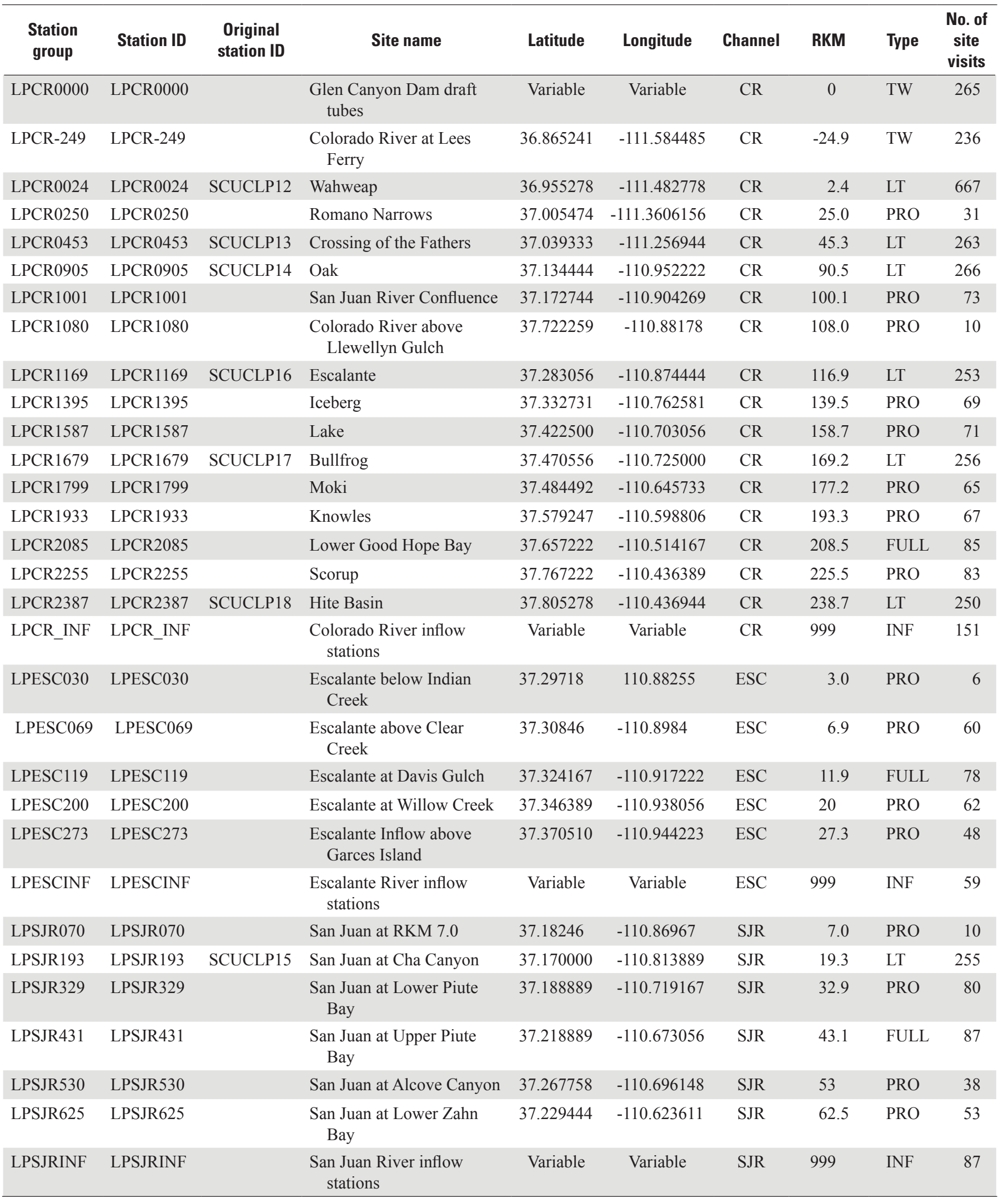




\section{Initial Observations}

On arrival at a sampling location, the current date and time were recorded, which were used to nominally identify the site visit, depth profile, and all samples collected during the site visit. This information is stored in the DATE field of the SURFACE table in the WQDB. Because sampling activities at a given site may occur over a period as long as 2 hours, the time value is approximate and should be not construed to represent the actual time that a specific sample was collected. General meteorological observations were recorded describing cloud cover, wind speed and direction, air temperature, and wave height. The surface elevation of the lake was obtained from daily National Park Service (NPS) or Reclamation reports and the bottom depth was determined using a Lowrance X-16 sonar depth sounder.

These observations are descriptive of conditions at the surface of a reservoir site or at a stream location during a single site visit. They were recorded on the header of the field data sheet and form one observation in the data table SURFACE in the WQDB. Each observation in the SURFACE table is uniquely identified by the STATION_ID of the location being sampled and the DATE identified for the site visit, which are the key fields of the SURFACE data table.

Secchi-depth transparency observations were made by using both the unaided eye and a subsurface viewing scope. Secchi-depth readings were recorded using a standardized 20 -cm disk with alternating quadrants of black and white. The Secchi disk was attached to a metric surveyor's tape with gradations in centimeters. Secchi-depth transparency was determined by lowering the disc from the shady side of the boat to a depth at which it disappeared from view and the depth was then recorded to the nearest decimeter. This observation was made over a sufficient time to allow for variations in surface disturbance and glare. Frequently, several measurements were made by different observers to compensate for variations in the subjective observations made by individuals (Wetzel and Likens, 1991).

Secchi-depth transparency observations in Lake Powell began in 1984. After 1994, a subsurface viewing scope (Lawrence Enterprises, Aqua Scope II) was employed to eliminate effects of glare or surface disturbances, and all Secchi depth observations more than $1 \mathrm{~m}$ in depth were recorded with both the viewing scope and the unaided eye. Secchi depths observed with the viewing scope are usually greater than those obtained by the unaided eye and show less variation under different conditions. The Secchi depth, observer's initials, whether or not a viewing scope was used, and a condition code describing the quality of observation conditions (for example, water glare, wave action, sun angle) were noted on the field data sheet. Several Secchi-depth transparency observations may be recorded during each site visit at a reservoir sampling location and are stored in the SECCHI table of the WQDB, which is linked to the SURFACE site visit table by STATION_ID and DATE. See the appendix for further details about the SECCHI table.

\section{Physicochemical Profiles}

\section{Objectives}

The main objective of the profiling effort was to characterize the major limnological strata in the water column with sufficient resolution to accurately define boundaries of the strata and identify other significant phenomena such as inflow density currents and depths at which dissolved oxygen minima or maxima occur.

Measurements of common physical and chemical water-quality parameters were routinely collected during the reservoir surveys, continuously in the tailwater below Glen Canyon Dam, and in conjunction with the collection of all chemical samples. Until April 2009, most of these measurements were collected using a multiparameter instrument, such as a Hydrolab 8000 Surveyor II or Surveyor $3 / \mathrm{H}_{2} 0$. These measurements included temperature in degrees Celsius $\left({ }^{\circ} \mathrm{C}\right)$, specific conductance, in microSiemens per centimeter $(\mu \mathrm{S} / \mathrm{cm}), \mathrm{pH}$ in standard units, dissolved oxygen in milligrams per liter $(\mathrm{mg} / \mathrm{L})$, turbidity in Nephelometric Turbidity Units (NTU), and oxidation-reduction potential in millivolts (mV) (table 4). From June 2009 to June 2010, depth profiles were collected with a Eureka Environmental, Inc., Manta/Amphibian profiling system recording the same parameters. After 2009, reservoir profiles were collected with a Seabird Electronics SBE19plus-V2. This instrument collects a continuous profile of the above parameters at a rate of four measurements per second during its descent and ascent through the water column. Post-processing of the collected data yields a profile of values at $0.5-\mathrm{m}$ intervals throughout the water column. These measurements are stored in the PROFILES table of the WQDB. See the appendix for further details about the PROFILES table.

Temperature and specific conductance are important in reservoir surveys for defining the density-controlled stratification patterns and determining the depth at which inflow currents enter and flow through the reservoir. Temperature is also a major regulatory factor in determining the rates of chemical and biological processes. Specific conductance is an indirect measure of salinity and is an indicator of the amount of dissolved minerals in the water.

Dissolved oxygen is important for biological processes in aquatic systems. Most aquatic organisms require adequate concentrations of dissolved oxygen to maintain life. Anoxia, or the absence of dissolved oxygen, can result in chemically reducing conditions, the generation of hydrogen sulfide, and the release of contaminants from the sediments. In the reservoir, dissolved oxygen concentrations help indicate the relative age of inflow currents, the amount of primary productivity, the amount of decomposition of organic and inorganic matter in a particular stratum, and the suitability of the water for release to downstream organisms. Oxidation-reduction potential (ORP) can be used to determine when chemically reducing conditions form after anoxia develops. 
The $\mathrm{pH}$ of water is affected by biological and chemical processes such as respiration and photosynthesis and is directly related to the amount of dissolved carbon dioxide and the degree of buffering in the water from biological or atmospheric processes. Turbidity is used to track inflow currents, indicating the concentration of organic or inorganic particles and the amount of light available underwater.

\section{Historical Methods, 1964-90}

During phases 1 and 2 (1965-81, table 1), original field notes were not maintained. Available information from field sampling is limited to a list of samples collected for each station and usually exists as type written information. It is difficult to determine exactly what methodologies and instrumentation were used during this time. Samples were collected from near the surface, near the bottom, and at standardized $50-\mathrm{ft}$ depth intervals, corresponding to even 50-ft increments in elevation above mean sea level, throughout the water column. Measurements were made in vitro aboard the sampling vessel from collected samples. Water temperature was measured with a handheld thermometer to the nearest degree Fahrenheit. Dissolved oxygen was determined by Winkler titration. After February 1973, an electrometric dissolved oxygen meter was used. Occasional $\mathrm{pH}$ determinations were made by unknown methods. Specific conductance was determined in the laboratory with analysis of major ion concentrations.

During phase 3 (1982-90, table 1), sampling frequency was gradually reduced from monthly reservoir-wide surveys to a single annual survey. During this period, the number of measurements within a profile was occasionally increased to provide more definition between depths in areas of rapidly changing conditions, while maintaining the measurements at $50-\mathrm{ft}$ depth intervals described above. This period coincided with a series of extremely high-flow years in the Colorado River Basin, with high inflows into Lake Powell and high releases from Glen Canyon Dam.

Beginning in March 1982, a Hydrolab System 8000 was used, allowing multiparameter measurements to be made throughout the water column. This instrument recorded temperature, specific conductance, $\mathrm{pH}$, dissolved oxygen, and oxidation-reduction potential; however, oxidationreduction potential was not consistently recorded until April 1988. For much of this period, problems were encountered with dissolved oxygen measurements, often resulting in abnormally high readings. In April 1988, the profiling instrument was replaced with a Hydrolab Surveyor II multiparameter profiling system. This system resolved the previous dissolved oxygen measurement problems.

\section{Current Methods, 1990-2013}

During the initial part of phase 4 (1990-94) (table 1), the Hydrolab Surveyor II was used to collect depth profiles for common physicochemical parameters. During this period, a Hydrolab 5100A datalogger was occasionally used to electronically transfer data to data-management systems. The number of sampling stations was increased to provide greater longitudinal resolution in the reservoir and its larger tributaries. From August 1990 to September 1991, monthly depth profiles were collected in the forebay of the reservoir by the USGS (Hart and Sherman, 1996). Those measurements are included in this report and the WQDB.

From March 1994 to April 2009, depth profiles were collected with the Hydrolab Surveyor $3 / \mathrm{H}_{2} 0$ multiparameter measurement system. This system measured temperature, specific conductance, dissolved oxygen, $\mathrm{pH}$, oxidation-reduction potential, and turbidity. Formal calibration procedures were followed, according to established protocol and manufacturers guidelines, in a controlled laboratory setting before and after use in the field. Accuracy checks were occasionally made while in the field, but field calibration was avoided due to the relatively unstable field environment that could affect the equilibrium of the individual sensors. The Hydrolab $\mathrm{H}_{2} 0$ sonde was connected to the Surveyor 3 display unit, which received a signal from the sonde for shipboard display and storage of the profile readings. These units were connected by a $165-\mathrm{m}$ underwater cable mounted on a 110 VAC motorized reel. A small handheld computer (HP 200LX) was connected to the Surveyor 3 and was used to view the readings from the display unit and temporarily store those readings for immediate display after the profile was completed. Immediately reviewing these data allowed for the identification of specific depths for chemical sampling in the water column. Permanent readings were stored in the Surveyor 3 for subsequent downloading and processing.

After the initial surface observations (for example, bottom depth, Secchi depth, weather observations) were made, the depth profile was collected. The Hydrolab $\mathrm{H}_{2} 0$ sonde was lowered to selected depths throughout the water column, and readings were stored in the Surveyor 3 datalogger after equilibration at a given depth was achieved and readings had stabilized.

Initial readings were taken immediately below the surface and at approximately 0.5 - to $1.0-\mathrm{m}$ intervals below the water surface for the first few meters to document surface warming phenomena. Below these near-surface measurements, the "Rule of Fives" was observed to determine intervals between measurements. This guideline states that if the value of any parameter changes by more than a decimal fraction of five (that is, $0.5^{\circ} \mathrm{C}$ for temperature, $0.5 \mathrm{mg} / \mathrm{L}$ dissolved oxygen, 0.05 units for $\mathrm{pH}$, or $50 \mu \mathrm{S} / \mathrm{cm}$ for specific conductance), a smaller depth interval should be chosen, with $0.5 \mathrm{~m}$ being the minimum interval. If parameters were not changing at this rate, a larger interval (as much as $5 \mathrm{~m}$ ) was selected. This guideline resulted in sufficient vertical resolution in the profile while allowing for a reasonable time at each station to collect the profile and allow full equilibration between measurements. Efforts were made to obtain measurements as close to the bottom as possible without disturbing bottom sediments that could foul sensors and cause ambiguous readings. This was accomplished by the vessel operator viewing the sonde on the sonar depth sounder as it was lowered through the water column. 
From June 2009 to June 2010, depth profiles were collected with a Eureka Environmental, Inc., Manta/Amphibian profiling system. Methods remained similar to those employing the Hydrolab Surveyor 3 during this period.

After October 2009, depth profiles were collected with the Seabird Electronics SBE19plus-V2 conductivity/temperature/ depth (CTD) profiler. This instrument pumps water at a constant rate through its temperature, conductivity, and dissolved oxygen sensors. Sensors for turbidity, pH, ORP, and chlorophyll florescence are positioned external to the CTD. Sensors are scanned at 0.25 -second intervals as the instrument is lowered and raised through the water column. Post-processing of the data collected by this instrument results in a profile of downcast readings averaged in $0.5-\mathrm{m}$ depth intervals.

After the profile was collected, the stratification of the water column was determined and major strata (epilimnion, metalimnion, hypolimnion, inflow layers) were identified from the tabular and graphical display of data recorded on the handheld computer. From this information, discrete chemical sampling depths were determined, based on the sampling objectives described below.

The values recorded at a specific depth are descriptive of the physical conditions at that point in the water column and form one observation in the WQDB table PROFILE, uniquely identified by STATION_ID, DATE, and DEPTH of the reading. The entire depth profile for a given site is composed of many PROFILE observations, which are associated with the SURFACE table by the common fields of STATION_ID and DATE. See the appendix for further details about the PROFILE table.

\section{Chemical Sampling and Processing}

\section{Objectives}

Water samples were collected at various depths at designated sites on Lake Powell for the determination of major ion and nutrient concentrations. The main objective of the sampling effort was to characterize chemical conditions near the surface, near the bottom, and in each major stratum of the water column. A secondary objective was to describe unusual phenomena that may occur at specific depths such as a metalimnetic oxygen deficit or an inflow plume flowing into an intermediate layer in the reservoir. Water samples for major ion and nutrient analysis were collected to characterize the overall chemical makeup and nutrient concentrations of the water being sampled. Nutrient compounds support primary productivity in the reservoir and the downstream aquatic ecosystem.

\section{Historical Methods, 1964-90}

During phases 1, 2, and 3 (1964-90) (table 1), samples were only collected for the analysis of major ion concentrations, specific conductance, total dissolved solids, $\mathrm{pH}$, hardness, and alkalinity. Samples were collected from near the surface, near the bottom, and at 50-ft depth intervals, corresponding to even 50 -ft increments in elevation above mean sea level, throughout the water column at each of seven original stations listed in table 2. No filtration, refrigeration, or preservation were performed. Approximately 65 to 70 samples were collected for a single reservoir-wide survey. These samples were analyzed by Reclamation's Upper Colorado Regional Laboratory in Salt Lake City, Utah.

\section{Current Methods, 1990-2013}

During phase 4 (1990-2013), sampling for nutrient concentrations began. Filtration and preservation were performed at each site, and samples were refrigerated immediately after collection. The sample collection was changed from even 50-ft depth intervals described above to variable depths so that fewer samples were collected at depths that more accurately represented major strata in the water column. The number of sampling sites during this period was increased to provide greater longitudinal resolution; however, chemical sampling was confined to a subset of these stations (approximately half of the 31 primary sites that are listed in table 3). Sampling for chlorophyll $a$, phytoplankton, zooplankton, and organic carbon began during this time; however, this information is not included in this report. From February 1995 to November 2005, alkalinity was determined in the field concurrently with the collection of water samples.

\section{Sample Collection}

Water samples were collected using Van Dorn samplers attached to a 160-m stainless-steel cable connected to a motorized winch. This task involved two people, one to operate the winch and one to attach and remove the samplers. The cable was marked at 1-m intervals to identify specific sampling depths. Samplers were lowered in a series to specified depths and were activated by a weighted messenger that travels down the cable. As one sampler was tripped, it released a second messenger that, in turn, actuated the sampler below, and so on.

From each water sample, four subsamples were obtained, which included two unfiltered $250-\mathrm{ml}$ samples and two $125-\mathrm{ml}$ filtered samples. The unfiltered subsamples were used for the laboratory determination of physicochemical properties (total suspended solids, $\mathrm{pH}$, specific conductance, and alkalinity) and total nutrients (total phosphorus and total Kjeldahl nitrogen). The filtered subsamples were used for the determination of major dissolved ion concentrations and dissolved nutrient compounds of phosphorus and nitrogen. Both nutrient samples were preserved with sulfuric acid in the amount described below.

All samples for chemical analysis were collected in highdensity polyethylene bottles that had been precleaned to U.S. Environmental Protection Agency (EPA) Contract Laboratory Program specifications (I-Chem 300 Series). The precleaning process involved acid washing and deionized water rinsing under controlled conditions to remove any impurities from 
storage conditions or the manufacturing process that may have affected the determination of low-level analytes.

\section{Sample Filtration}

All samples to be analyzed for the determination of dissolved substances were filtered through a $0.45-\mu \mathrm{m}$ polycarbonate-membrane filter in the field as soon as possible after collection (U.S. Environmental Protection Agency, 1983). This was accomplished using a peristaltic pump (Geotech Series II) with silicon tubing connected directly to the Van Dorn sampler. A segmented flow of air and water was used to thoroughly rinse the pump tubing before connecting to the filter apparatus. The filter apparatus was a 47-mm inline filter holder (Millipore Swinnex 47) housing a $47-\mathrm{mm}, 0.45-\mu \mathrm{m}$ polycarbonate-membrane filter, low in water extractable compounds (Poretics \#1035, lo extractable). After approximately 50 to $100 \mathrm{ml}$ passed through the filter apparatus, the filtered subsamples were collected.

\section{Preservation}

All samples for water-quality analysis were stored on ice. In addition, the nutrient samples were acidified with $1.2 \mathrm{~N} \mathrm{H}_{2} \mathrm{SO}_{4}$ in a proportion of $1 \mathrm{ml}$ of acid per $250 \mathrm{ml}$ sample. The acid preservation solution was supplied by the laboratory performing the sample analysis. The purpose of preserving samples was to (1) retard biological activity, (2) reduce chemical changes occurring between collection and analysis, (3) reduce volatility of constituents, and (4) reduce adsorption affects with the sample container.

\section{Transportation and Shipment}

Samples were stored on ice in coolers for the duration of the reservoir survey. On return from the field, samples were checked to ensure all samples were accounted for and proper documentation has been performed. The coolers were re-iced and shipped overnight to a designated laboratory for analysis.

\section{Documentation}

The depths of all samples collected at a specific station were noted on the field sheet. The four bottles representing the nutrient and major-ion subsamples were treated as a single sample. Quality-assurance samples collected at a given station were treated and numbered in the same manner as all other samples.

Starting with the first sample of the trip, a sequential field number was assigned to each sample for identification and tracking purposes. This number was recorded on the cap of each bottle as well as on the field sheet and sample labels. Each subsample received a label that identified the station code and name, sampling time and depth, field number, type of analysis requested, and the presence of any preservative.
Water-resistant label materials and inks were used to prevent damage from submersion.

The combination of station code, time, and depth of sampling uniquely identify each sample collected. These fields and other information pertaining to the sample, such as laboratory ID numbers for each analysis, constitute one observation in the WQDB SAMPLES table. The SAMPLES table is used to link sample collection information with site visit information in the SURFACE table, over the common fields STATION_ID and DATE. Analytical results from the laboratory, which are contained in the tables MAJOR IONS and NUTRIENTS, are linked to the SAMPLES table through laboratory identification numbers (LAB\#MAJ and LAB\#NUT). See the appendix for further details about the SAMPLES table.

\section{Quality Assurance/Quality Control}

Quality-assurance/quality-control (QA/QC) procedures are a critical part of the Lake Powell chemical sampling program to verify the accuracy and precision of laboratory analyses and verify the absence of contamination from the sampling process. Three types of QA/QC samples were collected: blank samples, blind replicates, and known-addition (spike) samples. Throughout the course of a reservoir survey, QA/QC samples made up approximately 10 percent of the total number of collected samples.

\section{Blank Samples}

Blank samples are used to determine the presence of, or verify the absence of, any contamination in the sampling or sample-processing efforts. Two types of blank samples were collected. An equipment blank was used to determine the amount of contamination from any aspect of the sampling or sample processing steps. For this sample, reagent-grade water was passed through every step of the sample processing process. The Van Dorn sampler was rinsed three times with reagent-grade water and then filled with a sufficient volume to fill all sample bottles. This water was used to rinse the filter apparatus in the same manner that an actual sample was processed and finally collected in precleaned sample bottles. Equipment blanks for nutrient analysis were preserved with sulfuric acid; unfiltered blanks were not passed through the filtration apparatus. Any detectable analyte measured in equipment-blank samples indicates contamination occurring somewhere in the sampling process. These samples are identified and stored in the WQDB with a STATION_ID value of "LPQC-EB."

A reagent blank is used to verify the presence or absence of contamination in the precleaned sampling bottles, rinse water, or the acid solution used to preserve samples. Reagent-grade water was transferred directly into precleaned sample bottles and preserved as appropriate for the analysis. The water did not come into contact with any sampling equipment, and no filtration step was performed (although the 
bottles for dissolved-constituent analysis were still labeled as being filtered). Any detectable analyte measured in reagentblank samples indicates contamination from sources other than the sampling or filtration apparatus. These samples are identified and stored in the WQDB with a STATION_ID value of "LPQC-RB."

\section{Replicate Samples}

Replicate samples are used to determine the precision of a sampling or analytical technique. Replicates resulting from multiple sampling efforts at a given location are used to evaluate the variability or precision of sampling activities. This type of replicate, however, was not routinely collected as part of the Lake Powell monitoring program. Because of the large volume of the horizontally stratified reservoir represented by a sample collected from a site at a given depth, it was assumed that the variability of samples collected from repeated efforts at that site and depth was low.

Replicates resulting from a single sampling effort, referred to as laboratory replicates, are used to evaluate the precision of the laboratory analytical process. These samples were collected from a continually mixed sampler and identified as two separate samples. Both samples were identified by the actual STATION_ID and DATE of the site visit; however, the first sample collected was identified by the actual DEPTH of the collected sample, and the second sample was identified by a fictitious depth (greater than the site depth) and identified as a replicate on the field sheet. By use of this means of identification, the two samples appeared to the analytical laboratory as two discrete samples, although they were identical replicates.

\section{Known-Addition Samples}

Known-addition (spike) samples are used to determine the accuracy of an analytical process and to ascertain the loss of a particular analyte from volatilization or adsorption. To evaluate these characteristics, a field spike was prepared by collecting a known volume of a laboratory replicate of the sample and adding a specific volume of a solution of known concentration. This spike solution, usually prepared by the laboratory performing the analysis, was prepared with known concentrations of the nutrient compounds that were to be determined. The solution contained concentrations of $10 \mathrm{mg} / \mathrm{L}$ soluble reactive phosphorus (SRP) $\left(\mathrm{PO}_{4}\right.$ as $\left.\mathrm{P}\right), 100$ $\mathrm{mg} / \mathrm{L}$ nitrate nitrogen $\left(\mathrm{NO}_{3}\right.$ as $\left.\mathrm{N}\right)$, and $10 \mathrm{mg} / \mathrm{L}$ ammonia nitrogen $\left(\mathrm{NH}_{4}\right.$ as $\left.\mathrm{N}\right)$. Volumes of the spike solution were added to a measured volume of filtered or unfiltered sample such that the resulting concentrations were within the detectable range of the analysis and not more than 10 times the concentration of the sample itself. The resulting spiked sample was then transferred directly to sample bottles. When possible, a large Van Dorn or other type sampler (Wildco 6.2 1 Beta Bottle \#1900) was used for this type of sample so that the original sample, the laboratory replicate, and the spike could be collected from the same sampler. As with the laboratory replicate, the spike sample was identified by the actual STATION_ID and DATE of the site visit but was given a fictitious depth and identified as a spike sample with the sample volume, concentration of spike solution, and volume of spike solution on the field sheet.

Another type of known-addition sample, a reagent spike, was prepared by adding a known amount of spike solution to reagent-grade water. The purpose of this type of spike sample is to provide a measurement of analytical accuracy in the absence of any sample matrix effects and to verify the concentration of the spike solution being used. These samples are identified and stored in the WQDB with a STATION_ID value of "LPQC-RS."

\section{Analytical Methods}

During phases 1, 2, and most of phase 3 of the monitoring program (1965-87) (table 1), all samples collected from Lake Powell were analyzed by Reclamation's Upper Colorado Regional Soils Laboratory in Salt Lake City, Utah. From September 1987 to November 2004, most samples for chemical constituents were analyzed by Reclamation's Environmental Chemistry Laboratory at the Technical Service Center in Denver, Colorado. Beginning in December 2004, all samples were analyzed by Reclamation's Lower Colorado Regional Laboratory in Boulder City, Nevada.

Laboratory analysis included determination of specific conductance, $\mathrm{pH}$, total alkalinity, total dissolved solids, total suspended solids, dissolved major ions (sodium, calcium, magnesium, potassium, sulfate, chloride, carbonate, and bicarbonate), and nutrients (total phosphorus, soluble reactive phosphorus, dissolved ammonia nitrogen, dissolved nitrate plus nitrite nitrogen, total Kjeldahl nitrogen, and total nitrogen). These analytes, their reporting units, detection limits, and references to EPA analytical methods are listed in table 4.

\section{The WODB}

The WQDB contains the information collected from the long-term water-quality monitoring program for Lake Powell and has been developed and maintained by the GCMRC. WQDB is a Microsoft Access database and has a relational structure, meaning that information pertaining to different types of data is stored in separate tables, which are linked by common fields to display various types of data from the monitoring program. The data presented in WQDB are in raw form and have undergone preliminary editing but have not been rigorously scrutinized or adjusted, and therefore, the data contained in WQDB are provisional and should be used with some degree of caution. A brief description of the included tables contains the general content of each table and how it relates to other tables. The linkages that exist between the various tables are graphically represented in figure 4 . 
Table 4. Detection limits, units, and U.S. Environmental Protection Agency (EPA) methods for Lake Powell chemical analyses. [--, no data; N/A, not applicable]

\begin{tabular}{|c|c|c|c|c|}
\hline Analyte & Symbol & Sample units & Detection limit & EPA method \\
\hline \multicolumn{5}{|c|}{ Physicochemical (Hydrolab profiles) } \\
\hline Temperature & $\mathrm{T}$ & ${ }^{\circ} \mathrm{C}$ & -- & -- \\
\hline Specific conductance & Sp. Cond. & $\mu \mathrm{S} / \mathrm{cm}$ & -- & -- \\
\hline $\mathrm{pH}$ & $\mathrm{pH}$ & $\mathrm{pH}$ & -- & -- \\
\hline Dissolved oxygen & DO & $\mathrm{mg} / \mathrm{L}$ & -- & -- \\
\hline Oxidation-reduction & ORP & $\mathrm{mV}$ & -- & -- \\
\hline Turbidity & Turb & NTU & -- & -- \\
\hline \multicolumn{5}{|c|}{ Physicochemical and major ions (laboratory analyses) } \\
\hline Specific conductance & Lab EC & $\mu \mathrm{S} / \mathrm{cm}$ & 2.0 & 120.1 \\
\hline $\mathrm{pH}$ & $\mathrm{pH}$ & $\mathrm{pH}$ & $\mathrm{N} / \mathrm{A}$ & 150.1 \\
\hline Total suspended solids & TSS & $\mathrm{mg} / \mathrm{L}$ & 4 & 160.2 \\
\hline Total dissolved solids & TDS & $\mathrm{mg} / \mathrm{L}$ & 10 & 160 \\
\hline Dissolved calcium & $\mathrm{Ca}$ & $\mathrm{mg} / \mathrm{L}$ & 0.03 & 200.7 \\
\hline Dissolved magnesium & $\mathrm{Mg}$ & $\mathrm{mg} / \mathrm{L}$ & 0.03 & 200.7 \\
\hline Dissolved sodium & $\mathrm{Na}$ & $\mathrm{mg} / \mathrm{L}$ & 0.03 & 200.7 \\
\hline Dissolved potassium & K & $\mathrm{mg} / \mathrm{L}$ & 1.0 & 200.7 \\
\hline Dissolved carbonate & $\mathrm{CO}_{3}=$ & $\mathrm{mg} / \mathrm{L}$ & 1.0 & 310.1 \\
\hline Dissolved bicarbonate & $\mathrm{HCO}_{3}^{-}$ & $\mathrm{mg} / \mathrm{L}$ & 1.0 & 310.1 \\
\hline Dissolved chloride & $\mathrm{Cl}^{-}$ & $\mathrm{mg} / \mathrm{L}$ & 1.0 & 300 \\
\hline Dissolved sulfate & $\mathrm{SO}_{4}=$ & $\mathrm{mg} / \mathrm{L}$ & 1.0 & 300 \\
\hline Dissolved silica & $\mathrm{SiO}_{2}$ & $\mathrm{mg} / \mathrm{L}$ & 0.02 & 200.7 \\
\hline Total alkalinity & $\mathrm{CaCO}_{3}$ & $\mathrm{mg} / \mathrm{L}$ & & Calc. \\
\hline \multicolumn{5}{|c|}{ Nutrients } \\
\hline Total phosphorus & TP-P & $\mathrm{mg} / \mathrm{L}$ & 0.005 & 365.1 \\
\hline Soluble reactive phosphorous & OP-P & $\mathrm{mg} / \mathrm{L}$ & 0.005 & 365.1 \\
\hline Ammonia & $\mathrm{NH}_{3}-\mathrm{N}$ & $\mathrm{mg} / \mathrm{L}$ & 0.01 & 350.1 \\
\hline Nitrate + nitrite & $\mathrm{NO}_{3}+\mathrm{NO}_{2}-\mathrm{N}$ & $\mathrm{mg} / \mathrm{L}$ & 0.03 & 353.2 \\
\hline Total Kjeldahl nitrogen & TKN-N & $\mathrm{mg} / \mathrm{L}$ & 0.05 & 351.4 \\
\hline
\end{tabular}

Further details of the structure and content of each of the specific tables are discussed in the appendix.

\section{Site Locations}

The STATIONS table (tblStations) contains information pertaining to current and historic sampling sites on Lake Powell and in Glen Canyon Dam releases. A sampling site must have a record in this table before any information can be stored in WQDB for that site. Each record in the STATIONS table is uniquely identified by the STATION ID field, an eight-character alphanumeric string. Under the current naming scheme, this station code identifies a sampling location and specifies the stream channel in which it is located and its distance from a given reference point.
Each record in the STATIONS table contains other pertinent information, such as the name of the site (SITE NAME), geographical coordinates (LATITUDE and LONGITUDE), the tributary arm in which it is located (CHANNEL), and its river-channel distance in the tributary arm, in kilometers from a given reference point (RKM). Also included is the STATION GROUP field, which collectively groups various multiple records in the STATIONS table that represent a single sampling location, and the PRIMARY GROUP field, which identifies the 31 primary station groups of the current and long-term monitoring program. These sites are listed in table 3 .

Details of the structure and content of the STATIONS table, the STATION ID naming conventions, and the STATION GROUP field are contained in the appendix. 


\section{Site Visits}

The SURFACE table (tblSURFACE) contains a record of each site visit that has been made to a particular sampling location and contains general observations pertaining to that site visit. These observations include reservoir surface elevation, identification of observers and instrumentation, air temperature, wind direction and speed, and cloud cover. This table represents the primary information by which all other measurements and observations are linked. A record for a specific site visit must be present in the SURFACE table before any observations can be stored related to that site visit. Each site visit is uniquely identified by a STATION ID and DATE. The DATE field is the date and time of the site visit. The time is a nominal representation of when the site visit occurred. In other words, although a site visit may take place over a time span of up to several hours, one representative time is selected to identify that site visit. All other data collected as part of that site visit are identified with the nominal site visit time.

Details of the structure and content of the SURFACE table are contained in the appendix.

\section{Secchi-depth Transparency}

The SECCHI table (tblSECCHI) contains multiple observations of Secchi-depth transparency for a given site visit. Because of the subjectivity of this measurement, multiple measurements among different observers, with and without the aid of a viewing scope, are often recorded. This creates a oneto-many relationship (one site visit with many Secchi-depth measurements) and requires these data to be contained in a separate table that is linked to the SURFACE table over the common fields STATION ID and DATE. Observations are uniquely identified by the STATION ID and DATE fields, along with an identifier for the observer and whether a viewing scope was used.

Details of the structure and content of the SECCHI table are contained in the appendix.

\section{Physical Profiles}

The PROFILES table (tblPROFILES) contains the results of multiparameter depth profiles of water-quality conditions throughout the water column at each sampling location. This table also contains single observations made at well-mixed stream sites. Each measurement at a discrete depth in the water column constitutes a record in the PROFILES table. A one-tomany relationship exists between the SURFACE table and the PROFILES table, with records linked by the common fields STATION ID and DATE. Each record is uniquely identified by STATION ID, DATE, and DEPTH in the PROFILES table. Remaining fields in the PROFILES table include water temperature (T), specific conductance (COND), dissolved oxygen (DO), $\mathrm{pH}(\mathrm{PH})$, oxidation-reduction potential (REDOX), and turbidity (TURB).

Details of the structure and content of the PROFILES table are contained in the appendix.

\section{Chemical Analyses}

\section{Sample Catalog}

The SAMPLES table (tblSAMPLES) contains a listing of all water-quality samples for chemical analysis collected during a given site visit. Each record is uniquely identified by the fields STATION ID, DATE, and DEPTH and link to the SURFACE table. There is a one-to-many relationship between the SURFACE table and the SAMPLES table over common values of the STATION ID and DATE fields. Each record contains a field collection identification code (a sequential number for all samples collected as part of a given field survey) and laboratory identification numbers for major ion and nutrient analyses to link with the analytical results in the MAJOR IONS and NUTRIENTS tables for a given sample.

Details of the structure and content of the SAMPLES table are contained in the appendix.

\section{Alkalinity Determinations}

The ALKALINITY table (tblALKALINITY) contains the results field titrations for total alkalinity of samples collected for chemical analysis. Occasionally, more than one alkalinity determination was done for a given sample, creating a oneto-many relationship over the common fields STATION ID, DATE, and DEPTH, that link the SURFACE table with the ALKALINITY table. Field alkalinity determinations began in February 1995 and were discontinued after November 2005.

Details of the structure and content of the SAMPLES table are contained in the appendix.

\section{Major Ion Concentrations}

The MAJOR IONS table contains the results of laboratory analyses for determinations of major ionic constituents. It is linked with a one-to-one relationship with the SAMPLES table over the common field LAB\#MAJ, which is also the unique identifier for any record in this table. This table includes concentrations for each of the commonly occurring cations and anions and laboratory-determined values for $\mathrm{pH}$, specific conductance, total dissolved solids, and total alkalinity. Associated with each analyte is a flagging field. The flagging field (with a suffix of "_FLG") contains a remark code indicating whether a value was below detection limits. In the case of a value reported below detection limits, the flagging field is given a remark code of " $<$ " and the value for the particular analyte's field is set to the stated detection limit value for that analyte at the time of analysis

\section{Nutrient Concentrations}

The NUTRIENTS table contains the results of laboratory analyses for nutrient concentrations. It is linked with a one-to-one relationship with the SAMPLES table over common values of the field LAB\#NUT, which is also the unique identifier for any 
record in this table. This table includes concentrations for total phosphorus (TP), soluble reactive phosphorus (SRP), dissolved ammonia nitrogen (NH3-N), dissolved nitrate and nitrite nitrogen (NO23-N), total Kjeldahl nitrogen (TKN-N), and total nitrogen (TN). Associated with each analyte is a flagging field. The flagging field (with a suffix of “_FLG”) contains a remark code indicating whether a value was below detection limits. In the case of a value reported below detection limits, the flagging field is given a remark code of " $<$ " and the value for the particular analyte's field is set to the stated detection limit value for that analyte at the time of analysis.

\section{Acknowledgments}

Data presented in this report were collected by various offices of the Reclamation and the USGS with the cooperation of the NPS Glen Canyon National Recreation Area. The author wishes to acknowledge and thank the following people for their assistance and participation in this data-collection effort. Reclamation boat pilots Larry Sanderson, John Parlett, Rick Leightner, Clarence Herron, and Calvin Leach provided logistical support for field activities conducted from 1964 through 1992. Technical field support since 1992 was provided by Robert Radtke, Nick Williams, Keri Stout, Jeanne Korn, and Mike Horn (Reclamation); Kevin Berghoff, Murph Doty, Mark Anderson, Jesse Granet, Carolyn Hackbarth, Jamie Pezja, and Sasha Rohde (NPS); and Susan Hueftle and Nick Voichick (USGS). Susan Hueftle provided direction of the biological component of this monitoring program, graphical analysis, and valuable insight into the hydrodynamic processes in the reservoir. Mentoring, guidance, and project leadership was provided by Jerry Miller and David Wegner (Reclamation); and Matthew Andersen, David Garrett, Barry Gold, Dale Robertson, Bob Hart, and Richard Marzolf (USGS). Many other people, too numerous to mention, also provided assistance and support; their participation and involvement is recognized and greatly appreciated. Since the inception of the Lake Powell Water Quality Monitoring Program, Reclamation has provided the primary funding for this program.

\section{References Cited}

Bureau of Reclamation, 1981, Water and Power ResourcesProject data: Denver, Colo., Bureau of Reclamation.

Bureau of Reclamation, 2007, Record of decision - Colorado River interim guidelines for lower basin shortages and the coordinated operations for Lake Powell and Lake Mead: Boulder City, Nevada, Bureau of Reclamation, 61 p., available at http://www.usbr.gov/lc/region/programs/strategies/ RecordofDecision.pdf.

Ferrari, R.L., 1988, 1986 Lake Powell Survey: Denver, Colo., Bureau of Reclamation.
Hart, R.J., and Sherman, K.M., 1996, Physical and chemical characteristics of Lake Powell at the forebay and outflow of Glen Canyon Dam, Northeastern Arizona, 1990-91: U.S. Geological Survey Water-Resources Investigations Report 96-4016, 78 p.

Hart, R.J., Taylor, H.E., Antweiler, R.C., Fisk, G.G., Anderson, G.M., Roth, D.A., Flynn, M.E., Peart, D.B., M. Truini, M., and Barber., L.B., 2005, Physical and chemical characteristics of Knowles, Forgotten, and Moqui Canyons, and effects of recreational use on water quality, Lake Powell, Arizona and Utah: U.S. Geological Survey Scientific Investigations Report 2004-5120, 43 p.

Marzolf, G.R., 1998, Depth profiles of temperature, specific conductance, and oxygen concentrations in Lake Powell, Arizona-Utah, 1992-95: U.S. Geological Survey Open-file Report 97-835, 119 p,

National Research Council, 1996, River resource management in Grand Canyon: Committee to Review the Glen Canyon Environmental Studies, Commission on Geosciences, Environment, and Resources: Washington, D.C., National Academy Press, 226 p.

Potter, L.D., and Drake, C.L., 1989, Lake Powell—Virgin flow to dynamo: University of New Mexico Press, 328 p.

Stanford, J.A., and Ward, J.V., 1991, Limnology of Lake Powell and the chemistry of the Colorado River, in Colorado River ecology and dam management: Washington, D.C., National Academy Press, p. 75-101.

U.S. Department of the Interior, 1996, Record of decision, operation of Glen Canyon Dam final environmental impact statement: Washington, D.C., Office of the Secretary of the Interior, $15 \mathrm{p}$.

U.S. Environmental Protection Agency, 1983, Methods for chemical analysis of water and wastes: Cincinnati, Ohio, U.S. Environmental Protection Agency, Environmental Monitoring and Support Laboratory, EPA-600/4-79-020.

Voichick, N., and Wright, S.A., 2007, Water-temperature data for the Colorado River and tributaries between Glen Canyon Dam and Spencer Canyon, Northern Arizona, 1988-2005: U.S. Geological Survey Data Series 251, 24 p., available at http://pubs.usgs.gov/ds/2007/251/.

Wetzel, R.G., and Likens, G.E, 1991, Limnological analyses, 2nd ed: New York, Springer-Verlag, 391 p. 
Appendix 


\section{Appendix-Database Table Descriptions}

This appendix contains a description of the various tables in the WQDB. Each section contains a brief description of each table, the fields and attributes of each table, notes about linkages to other tables, and summary statistics of each table. Under the FieldSize property for the data field in each table, "Single" refers to single-point precision, with a storage size of 4 bytes; "Double" refers to double-point precision, with a storage size of 8 bytes. Figure 4 shows the graphical relationships between the tables of the WQDB.

\section{Stations Table}

The Stations table (tblStations) describes the various sampling sites at which monitoring activities occur on Lake Powell. A single sampling site is identified by the 8-character STATION ID field, which uniquely identifies each record in the table. The fields in the STATIONS table are listed in table A-1.

The STATION ID field describes the location of a sampling site by including the stream channel in which it is located and the river-channel distance, in tenths of kilometers, from Glen Canyon Dam or a tributary confluence. Under the current naming convention, the first two letters reference the project (LP for Lake Powell), the next 2 or 3 characters designate the tributary arm or stream channel (CR for Colorado River, SJR for San Juan River, ESC for Escalante River), and the remaining 3 or 4 digits designate the riverchannel distance, in tenths of kilometers, of the station from a given reference point. That reference point is usually the confluence of a tributary arm with the main channel. For the Colorado River channel, the reference point is Glen Canyon Dam. For example, the Cha Canyon station, which is located 19.3 river-channel kilometers from the pre-dam Colorado River channel on the San Juan River arm of Lake Powell, has a value for the STATION ID field of LPSJR193. For stations below Glen Canyon Dam, the river-channel distance is negative. For example, LPCR-249 represents the Colorado River at Lees Ferry station, 24.9 river-channel kilometers below Glen Canyon Dam. The specific location for a given station is listed in the STATIONS table as latitude and longitude coordinates in decimal degrees.

Information regarding sampling locations is stored in WQDB according to the specific STATION ID in effect at the time of sampling and the more general STATION GROUP. Sampling locations representative of a given general location on the reservoir (STATION GROUP) may have many different STATION IDs recorded in the database. This is because different naming conventions have been used during the monitoring history of Lake Powell and because the specific sampling location for a given site may have been slightly adjusted over time to facilitate sampling conditions (because of boat traffic, wind patterns, or local sedimentation). Multiple
STATION ID values may also exist for tributary inflow sites on the reservoir and Glen Canyon Dam release sites. Depending on reservoir elevation at the time of sampling, the actual location of an inflow sampling site may vary over a relatively large distance. Releases from Glen Canyon Dam may be sampled from any of eight generating turbine draft tubes or from the tailrace immediately below Glen Canyon Dam. The STATION GROUP field is therefore used to collectively reference multiple STATION IDs to a single representative location on the reservoir. All records in the STATIONS table that are representative of a single location on the reservoir will have a common value for the STATION GROUP field. For example, the STATION GROUP values of LPCR_INF, LPSJRINF, and LPESCINF collectively group various inflow sites on the Colorado, San Juan, and Escalante River arms of the reservoir, respectively. The STATION GROUP value of LPCR0000 collectively groups all sampling locations representative of Glen Canyon Dam releases. By selecting all records in the STATIONS table for common values of a given STATION GROUP code, the entire history for that site can be retrieved, regardless of the specific STATION ID value in effect at the time of sampling.

There are 330 sampling sites described in the STATIONS table. Of this number, 234 correspond to the 31 primary station groups shown in table 3 . The remaining 92 sites represent occasional sampling and are not part of the current routine monitoring program. The 31 primary station groups represent the current monitoring program and long-term sampling sites. These groups are designated by the PRIMARY GROUP field. The geographical coordinates, stream channel designation, and river channel distances for the 31 primary groups are listed in table 3 .

\section{Surface Table}

The Surface table (tblSurface) contains a record of every site visit at which water-quality measurements have been made on Lake Powell. It contains observations made on arrival (DATE) at a given sampling site (STATION ID) and includes information about who collected the measurements and how they were collected, reservoir elevation and depth, general meteorological conditions and other comments. Each record is uniquely identified by the time of the site visit (DATE) and the location of the site visit (STATION ID). See table 3 for the number of Surface table entries or site visits for primary station groups.

The Trip ID field is a useful way to group all site visits within a given monitoring survey. The value of the Trip ID field is in the format LPyymmdd, where yymmdd corresponds to the date of the first reservoir sample collected during the monitoring survey. The fields constituting the Surface table are listed in table A-2.

There are currently 4,360 observations or site visits in the Surface table. Of this number, 4,084 (93.7 percent) represent site visits related to the 31 primary station groups shown in table 3 . 
The remaining 276 (6.3 percent) site visits represent occasional sampling at sites not part of the current monitoring program.

\section{Secchi Table}

The Secchi table (tblSecchi) contains a record of multiple Secchi-depth transparency observations made during each site visit. For a given site visit, multiple observers (OBSERVER) may record observations and each observation is made with or without the aid of an underwater viewing scope (SCOPE.) The viewing scope reduces the effects of glare and surface disturbance on the Secchi-depth transparency observation. Each Secchi-depth transparency observation is also assigned a condition code (CONDITIONS), with four primary designations_-E, excellent; G, good; F, fair; and P, poor-which indicate the observation conditions relating to surface glare, choppiness, boat movement, and others. Consistent documentation of observers, condition codes, and the use of the viewing scope began in 1995. Each record in the Secchi table is uniquely identified by the primary fields STATION ID, DATE, OBSERVER, and SCOPE. More than one Secchi-depth transparency observation may be made during a single site visit. The fields in the Secchi table are listed in table A-3.

There are currently 6,961 Secchi-depth transparency observations in the Secchi table, 6,530 of which have been recorded since 1995 and have relatively consistent documentation of observers, condition codes, and whether or not a viewing scope was used. Of the observations recorded since 1995, 6,168 (94.5 percent) are associated with the 31 primary station groups shown

Table A-1. Data fields and attributes of tblStations.

\begin{tabular}{llll}
\hline \multicolumn{1}{c}{ Field Name } & \multicolumn{1}{c}{ Type } & \multicolumn{1}{c}{ FieldSize } & \multicolumn{1}{c}{ Description } \\
\hline *STATION ID & Text & 10 & site identifier code \\
SITE NAME & Text & 50 & descriptive site name \\
LATITUDE & Number & Double & latitude (decimal degrees) \\
LONGITUDE & Number & Double & longitude (decimal degrees) \\
CHANNEL & Text & 5 & stream channel of site location \\
RKM & Number & Single & river channel distance (km) \\
STATION GROUP & Text & 10 & station grouping identifier \\
PRIMARY GROUP? & Yes/No & 1 & primary group designation \\
\hline
\end{tabular}

${ }^{*}$ Indicates primary field that uniquely identifies each record in the table.

Table A-2. Data fields and attributes of tblSurface.

\begin{tabular}{llll}
\hline Field Name & Type & FieldSize & \multicolumn{1}{c}{ Description } \\
\hline *STATION ID & Text & 10 & site identifier code \\
*DATE & Date/Time & 15 & date and time of site visit \\
TRIP ID & Text & 10 & monitoring survey identifier \\
PROFILERS & Text & 24 & names or initials of observers \\
INSTRUMENT & Text & 20 & designation of profiling instrument \\
VESSEL & Text & 20 & designation of sampling vessel \\
ELEVATION & Number & Single & reservoir elevation $(\mathrm{ft})$ \\
BOTTOM SOUNDING & Number & Single & bottom sounding $(\mathrm{m})$ \\
WAVE HEIGHT & Text & 20 & wave height description $(\mathrm{cm})$ \\
WIND & Text & 20 & wind speed description $(\mathrm{mph})$ \\
AIR TEMP & Number & Single & numeric air temperature \\
AIR TEMP UNITS & Text & 1 & air temperature units $\left({ }^{\circ} \mathrm{F} \mathrm{or}{ }^{\circ} \mathrm{C}\right)$ \\
CLOUD COVER & Text & 10 & cloud cover-verbal $(\%)$ \\
\hline
\end{tabular}

* Indicates primary fields that uniquely identify each record in the table. 
Table A-3. Data fields and attributes of tblSecchi.

\begin{tabular}{llrl}
\hline \multicolumn{1}{c}{ Field name } & \multicolumn{1}{c}{ Type } & Field size & \multicolumn{1}{c}{ Description } \\
\hline *STATION ID & Text & 10 & site identifier code \\
*DATE & Date/Time & 15 & date and time of site visit \\
*OBSERVER & Text & 5 & initials of observer \\
*SCOPE & Yes/No & 1 & viewing scope designation \\
SECCHI DEPTH & Number & Single & Secchi-depth transparency (m) \\
CONDITIONS & Text & 5 & viewing conditions (e, excellent; g, good; f, fair; p, poor) \\
\hline
\end{tabular}

"Indicates primary fields that uniquely identify each record in the table.

Table A-4. Data fields and attributes of tbIProfiles.

\begin{tabular}{llcl}
\hline Field Name & Type & FieldSize & \multicolumn{1}{c}{ Description } \\
\hline *STATION ID & Text & 10 & site identifier code \\
*DATE & Date/Time & 15 & date and time of site visit \\
*DEPTH & Number & Single & depth of observation $(\mathrm{m})$ \\
$\mathrm{T}$ & Number & Single & water temperature $\left({ }^{\circ} \mathrm{C}\right)$ \\
COND & Number & Single & specific conductance $(\mu \mathrm{S} / \mathrm{cm})$ \\
DO & Number & Single & dissolved oxygen $(\mathrm{mg} / \mathrm{L})$ \\
PH & Number & Single & pH (units) \\
ORP & Number & Single & oxidation-reduction potential $(\mathrm{mv})$ \\
TURB & Number & Single & turbidity $(\mathrm{NTU})$ \\
PTIME & Date/Time & 18 & actual time of single observation \\
\hline
\end{tabular}

* Indicates primary fields that uniquely identify each record in the table.

in table 3 . The remaining 362 (5.5 percent) represent occasional measurements at sites not part of the current monitoring program. There were 431 observations recorded before 1995, consisting mainly of single observations.

\section{Profiles Table}

The Profiles table (tblProfiles) contains a record of every discrete water-quality measurement for water temperature, specific conductance, $\mathrm{pH}$, dissolved oxygen, oxidation-reduction potential or turbidity collected during each site visit. This includes single observations from a hand-held thermometer or other instruments as well as depth profiles collected through the water column at a given location. Each record in the Profile table is uniquely identified by time of the site visit (DATE), the location of the observation (STATION ID), and the depth of the observation (DEPTH). The PTIME field identifies the instantaneous time at which an observation was recorded. The fields in the Profiles table are listed in table A-4.

There are currently 129,461 observations contained in the Profiles table. Of this number, 121,320 observations (93.7 percent) are associated with the 31 primary station groups shown in table 3 . The remaining 8,141 observations
(6.3 percent) represent occasional measurements at sites not part of the current monitoring program.

\section{Samples Table}

The Sample table (tblSamples) provides a catalog of all samples collected for chemical analysis during a given site visit and serves as a link between the Surface table (tblSurface) and the various tables representing the different categories of chemical analysis (tblAlkalinity, tblMajor Ions, and tblNutrients). Each record can be linked with a site visit record in the Surface table by the fields STATION ID, DATE, and DEPTH. Links with the corresponding analysis tables are made through laboratoryassigned sample identifier fields or, in the case of the Alkalinity table, through the STATION ID, DATE, and DEPTH fields. Each record in the Samples table is uniquely identified by time of the site visit (DATE), the location of the site visit (STATION ID), and the depth at which the sample was collected (DEPTH). A sequential sample number (FLD \#) is recorded for every sample collected during a given field survey to aid in sample tracking. The fields comprising the Samples table are listed in table A-5.

There are currently 12,315 samples contained in the Samples table. Of this number, 12,119 (98.4 percent) represent samples collected from the 31 primary station groups shown in table 3 . 
Table A-5. Data fields and attributes of tblSamples.

\begin{tabular}{llll}
\hline Field Name & Type & FieldSize & \multicolumn{1}{c}{ Description } \\
\hline *STATION ID & Text & 10 & site identifier code \\
*DATE & Date/Time & 15 & date and time of site visit \\
*DEPTH & Number & Single & depth of sample (m) \\
FLD $\#$ & Number & Single & trip-specific sample identifier \\
LAB\#MAJ & Text & 10 & major ion analysis sample identifier \\
LAB\#NUT & Text & 10 & nutrient analysis sample identifier \\
\hline
\end{tabular}

* Indicates primary fields that uniquely identify each record in the table.

Table A-6. Data fields and attributes of tblAlkalinity.

\begin{tabular}{llll}
\hline Field Name & Type & FieldSize & \multicolumn{1}{c}{ Description } \\
\hline *STATION ID & Text & 10 & site identifier code \\
*DATE & Date/Time & 15 & date and time of site visit \\
*DEPTH & Number & Single & depth of sample $(\mathrm{m})$ \\
*OBSERVER & Text & 5 & initials of observer \\
ALKALINITY & Number & Double & total alkalinity $\left(\mathrm{mg} / \mathrm{L}\right.$ as $\left.\mathrm{CaCO}_{3}\right)$ \\
\hline
\end{tabular}

*Indicates primary fields that uniquely identify each record in the table.

The remaining 196 samples (1.6 percent) represent occasional sampling at sites not part of the current monitoring program.

\section{Alkalinity Table}

The Alkalinity table (tblAlkalinity) contains the results of field determinations of total alkalinity on samples collected for chemical analysis. Each record in the Alkalinity table links with a record in the Samples table (tblSamples) by the fields STATION ID, DATE, and DEPTH. Because more than one field alkalinity determination may be made for a given sample, one or more records in the Alkalinity table can be linked to a single record in the Samples table. Each record in the Alkalinity table is uniquely identified by time of the site visit (DATE), the location of the site visit (STATION ID), and the depth at which the sample was collected (DEPTH). The fields in the Samples table are listed in table A-6.

There are currently 1,908 field alkalinity sample determinations in the Alkalinity table. These determinations were performed on samples collected between 1995 and 2005. Of this number, 1,843 ( 96.6 percent) represent samples collected from the 31 primary station groups shown in table 3 . The remaining 65 determinations (3.4 percent) represent occasional sampling at sites not part of the current monitoring program. No alkalinity determinations have been performed in the field since November 2, 2005.

\section{Major Ions Table}

The Major Ions table (tblMajor Ions) contains the results of chemical analyses for the major ionic constituents and other physical characteristics in water samples. Each record in the Major Ions table is uniquely identified by the LAB\#MAJ field. The fields with the "_FLG" suffix designate analytical values that were below the laboratory's stated detection limit for a given analyte. In those cases, the "_FLG" field for a particular analyte is given a remark code of " $<$ ", and the field representing the actual concentration of the analyte is given the stated detection limit at the time of analysis. It is important that both fields are incorporated in any reporting or analysis to indicate values that are below detectible limits. The fields constituting the Major Ions table are listed in table A-7.

There are currently 12,210 major-ion analyses in the Major Ions table. Of this number, 12,018 (98.4 percent) represent samples collected from the 31 primary station groups shown in table 3 . The remaining 192 analyses (1.6 percent) represent occasional sampling at sites not part of the current monitoring program.

\section{Nutrients Table}

The Nutrients table (tblNutrients) contains the results of chemical analyses for nutrient compounds of phosphorus and nitrogen. Each record in the Nutrients table is uniquely 
Table A-7. Data fields and attributes of tblMajor lons.

\begin{tabular}{|c|c|c|c|}
\hline Field Name & Type & FieldSize & Description \\
\hline *LAB\#MAJ & Text & 10 & laboratory sample identifier \\
\hline COND & Number & Single & lab-determined specific conductance \\
\hline $\mathrm{PH}$ & Number & Single & lab-determined $\mathrm{pH}$ \\
\hline TSS & Number & Single & total suspended solids $(\mathrm{mg} / \mathrm{L})$ \\
\hline TSS_FLG & Text & 5 & detection limit qualifier \\
\hline TDS & Number & Single & total dissolved solids $(\mathrm{mg} / \mathrm{L})$ \\
\hline TDS_FLG & Text & 5 & detection limit qualifier \\
\hline $\mathrm{CA}$ & Number & Single & dissolved calcium $(\mathrm{mg} / \mathrm{L})$ \\
\hline CA_FLG & Text & 5 & detection limit qualifier \\
\hline MG & Number & Single & dissolved magnesium $(\mathrm{mg} / \mathrm{L})$ \\
\hline MG_FLG & Text & 5 & detection limit qualifier \\
\hline NA & Number & Single & dissolved sodium $(\mathrm{mg} / \mathrm{L})$ \\
\hline NA_FLG & Text & 5 & detection limit qualifier \\
\hline $\mathrm{K}$ & Number & Single & dissolved potassium (mg/L) \\
\hline K_FLG & Text & 5 & detection limit qualifier \\
\hline $\mathrm{CO} 3$ & Number & Single & dissolved carbonate (mg/L) \\
\hline CO3_FLG & Text & 5 & detection limit qualifier \\
\hline $\mathrm{HCO} 3$ & Number & Single & dissolved bicarbonate (mg/L) \\
\hline HCO3_FLG & Text & 5 & detection limit qualifier \\
\hline ALAKALINITY & Number & Single & total alkalinity $\left(\mathrm{mg} / \mathrm{L}\right.$ as $\left.\mathrm{CaCO}_{3}\right)$ \\
\hline ALKALINITY_FLG & Text & 5 & detection limit qualifier \\
\hline CL & Number & Single & chloride $(\mathrm{mg} / \mathrm{L})$ \\
\hline CL_FLG & Text & 5 & detection limit qualifier \\
\hline SO4 & Number & Single & dissolved sulfate $(\mathrm{mg} / \mathrm{L})$ \\
\hline SO4_FLG & Text & 5 & detection limit qualifier \\
\hline $\mathrm{SIO} 2$ & Number & Single & dissolved silica (mg/L) \\
\hline SIO2_FLG & Text & 5 & detection limit qualifier \\
\hline FE & Number & Single & dissolved iron (mg/L) \\
\hline FE_Flg & Text & 5 & detection limit qualifier \\
\hline
\end{tabular}

" Indicates primary field that uniquely identifies each record in the table.

Table A-8. Data fields and attributes of tblNutrients.

\begin{tabular}{llll}
\hline Field Name & Type & FieldSize & \multicolumn{1}{c}{ Description } \\
\hline *LAB\#NUT & Text & 10 & laboratory sample identifier \\
TP & Number & Single & total phosphorus (mb/L) \\
TP_FLG & Text & 5 & detection limit qualifier \\
SRP & Number & Single & soluble reactive phosphorus (mg/L as P) \\
SRP_FLG & Text & 5 & detection limit qualifier \\
NH3-N & Number & Single & ammonium nitrogen $(\mathrm{mg} / \mathrm{L}$ as N) \\
NH3-N_FLG & Text & 5 & detection limit qualifier \\
NO23-N & Number & Single & nitrate+nitrite nitrogen $(\mathrm{mg} / \mathrm{L}$ as N) \\
NO23-N_FLG & Text & 5 & detection limit qualifier \\
TKN & Number & Single & total Kjeldahl nitrogen $(\mathrm{mg} / \mathrm{L})$ \\
TKN_FLG & Text & 5 & detection limit qualifier \\
TN & Number & Single & total nitrogen (mg/L) \\
TN_FLG & Text & 5 & detection limit qualifier \\
\hline
\end{tabular}

${ }^{*}$ Indicates primary field that uniquely identifies each record in the table. 
identified by the LAB\#NUT field. The fields with the "_FLG" suffix designate analytical values that were below the laboratory's stated detection limit for a given analyte. In those cases, the "_FLG" field for a particular analyte is given a remark code of " $<$ ", and the field representing the actual concentration of the analyte is given the stated detection limit at the time of analysis. It is important that both fields are incorporated in any reporting or analysis to indicate values that are below detectible limits. The fields in the Nutrients table are listed in table A-8.

There are currently 3,802 nutrient analyses in the Nutrients table. Of this number, 3,682 (96.8 percent) represent samples collected from the 31 primary station groups shown in table 3 . The remaining 120 analyses (3.2 percent) represent occasional sampling at sites not part of the current monitoring program. 
This page left intentionally blank. 
Produced in the Western Region, Menlo Park, California Manuscript approved for publication February 12, 2015

Text edited by James W. Hendley II

Layout and design by Jeanne S. DiLeo and Cory Hurd 


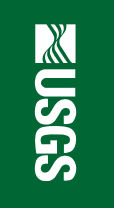

ISSN 2327-638X (online)

http://dx.doi.org/10.3133/ds471

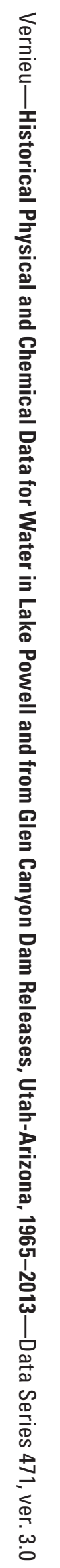

